\title{
Indian Antimicrobial Prescription Guidelines in Critically III Immunocompromised Patients
}

${ }^{1}$ Atul P Kulkarni, ${ }^{2}$ Manju Sengar, ${ }^{3}$ Girish Chinnaswamy, ${ }^{4}$ Ashit Hegde, ${ }^{5}$ Camilla Rodrigues, ${ }^{6}$ Rajeev Soman, ${ }^{7}$ Gopi C Khilnani, ${ }^{8}$ Suresh Ramasubban, ${ }^{9}$ Mukesh Desai, ${ }^{10}$ Rahul Pandit, ${ }^{11}$ Ruchira Khasne, ${ }^{12}$ Anjali Shetty, ${ }^{13}$ Trupti Gilada, ${ }^{14}$ Shilpushp Bhosale, ${ }^{15} \mathrm{Amol}$ Kothekar, ${ }^{16}$ Subhal Dixit, ${ }^{17}$ Kapil Zirpe, ${ }^{18}$ Yatin Mehta, ${ }^{19}$ Jacob George Pulinilkunnathil, ${ }^{20}$ Vikas Bhagat, ${ }^{21}$ Mohammad Saif Khan, ${ }^{22}$ Amit M Narkhede, ${ }^{23}$ Nishanth Baliga, ${ }^{24}$ Srilekha Ammapalli, ${ }^{25}$ Shrirang Bamne, ${ }^{26}$ SiddharthTurkar, ${ }^{27}$ Vasudeva Bhat K, ${ }^{28}$ Jitendra Choudhary, ${ }^{29}$ Rishi Kumar, ${ }^{30}$ Jigeeshu V Divatia

Keywords: immunocompromised patients, febrile neutropenia, solid organ transplant, Human Immunodeficiency Virus, Primary immunodeficiency disorders, asplenia

How to cite this article: Kulkarni AP, Sengar M, Chinnaswamy G, Hegde A, Rodrigues C, Soman R, Khilnani GC, Ramasubban S, Desai M, Pandit R, Khasne R, Shetty A, Gilada T, Bhosale S, Kothekar A, Dixit S, Zirpe K, Mehta Y, Pulinilkunnathil JG, Bhagat V, Khan MS, Narkhede AM, Baliga N, Ammapalli S, Bamne S, Turkar S, Bhat KV, Choudhary J, Kumar R, Divatia JV. Indian Journal of Critical Care Medicine 2019;23 (Suppl1):S64-S96.

Source of support: Indian Society of Critical Care Medieine Conflict of interest: None

\section{INTRODUCTION}

The number of admissions of immunocompromised patients in the Indian intensive care units (ICUs) is growing. This is because of availability of better treatments for acquired immunodeficiency states, increasing incidence and detection of cancer, with more aggressive therapies aimed at cancer cure, and increased expectations of better ICU outcomes in the cancer patient. ${ }^{1,2}$

The indications of immunosuppression have expanded, contributing to an increased number of immunocompromised patients. There is a sharp rise in the number of solid organ transplants being performed in India contributing to the increased number of patients with immunosuppression getting admitted to the ICU in immediate postoperative and subsequent follow-up period. In the pediatric population, we can recognize the genetic predisposition of patients to congenital immunodeficiency states. All these patients have greater susceptibility to new infections or reactivation of latent infections. ${ }^{3}$ Therefore, it is the need of the hour to develop

Corresponding author: Atul P Kulkarni, Professor and Head, Division of Critical Care Medicine, Department of Anaesthesiology, Critical Care and Pain, Tata Memorial Hospital, Homi Bhabha National Institute, Mumbai, Maharashtra, India. e-mail: kaivalyaak@yahoo.co.in
Indian guidelines for prescribing antimicrobial therapy in this population presenting to the ICU.

We feel that the outcomes are likely to be better if these immunocompromised patients with infectious diseases requiring ICU admission are preferably treated at a tertiary care center where all diagnostic facilities along with specialists in microbiology, immunology, infectious disease are likely to be available. We present guidelines in five separate sections: febrile neutropenic patients, patients who have undergone a solid organ transplant, patients with human immunodeficiency virus infections presenting to ICU, congenital asplenia or hyposplenia, and those with congenital primary immunodeficiency syndromes.

These guidelines were developed starting with a collection of Indian and other data which was communicated to members by electronic communication. A meeting of all committee members was held where the data was presented in the form of questions pertaining to the evidence, available evidence from Indian ICUs, and evidence statements and recommendations. A draft of each section was prepared and circulated and finally presented in another committee meeting. The final draft of guidelines was prepared and again communicated to members. The GRADE system was used for the quality of evidence and recommendations (Table 1).

Table 1: Quality of evidence and recommendations

\begin{tabular}{ll}
\hline Quality of Evidence & $\begin{array}{l}\text { Level of } \\
\text { evidence }\end{array}$ \\
\hline $\begin{array}{l}\text { Evidence from } \geq 1 \text { good quality and well conducted } \\
\text { randomized control trial(s) or meta-analysis of }\end{array}$ & 1 \\
$\begin{array}{l}\text { RCT's. } \\
\begin{array}{l}\text { Evidence from at least 1 RCT of moderate quality, } \\
\text { or well-designed clinical trial without randomization; } \\
\text { or from cohort or case-controlled studies. }\end{array}\end{array}$ \\
$\begin{array}{l}\text { Evidence from descriptive studies, or reports } \\
\text { of expert committees, or opinion of respected }\end{array}$ & 3 \\
$\begin{array}{l}\text { authorities based on clinical experience. } \\
\text { Not backed by sufficient evidence; however, a } \\
\text { consensus reached by the working group, } \\
\text { based on clinical experience and } \\
\text { expertise. }\end{array}$ & $\begin{array}{l}\text { Useful } \\
\text { Practice }\end{array}$ \\
\hline & $\begin{array}{l}\text { Points } \\
\text { (UPP) }\end{array}$ \\
\hline
\end{tabular}




\begin{tabular}{ll}
\hline Strength of Recommendation & Grade \\
\hline $\begin{array}{l}\text { Strong recommendation to do (or not to do) } \\
\text { where the benefits clearly outweigh the risk (or }\end{array}$ & A \\
vice versa) for most, if not all patients. & \\
$\begin{array}{l}\text { Weak recommendation, where benefits and risk } \\
\text { are more closely balanced or are more uncertain. }\end{array}$ & B
\end{tabular}

\section{PART 1. PATIENT WITH FEBRILE NEUTROPENIA IN THE INTENSIVE CARE UNIT}

Febrile neutropenia (FN) is defined as an oral temperature of $>38.3^{\circ} \mathrm{C}$ or two consecutive readings of $>38.0^{\circ} \mathrm{C}$ for 2 hours and an absolute neutrophil count (ANC) of $<0.5 \times$ $10^{9} /$ L or expected to fall below $0.5 \times 10^{9} / \mathrm{L}^{4}$

These guidelines are applicable to a critically ill febrile neutropenic patient presenting to the ICU, with any of the following clinical or laboratory parameters of organ failure but not limited to:

- Hypotension

- Tachypnoea requiring oxygen therapy more than 4 liters / minute to maintain saturation $>90 \%$

- Altered mental status (without focal neurological deficit)

- Oliguria or rising creatinine

\section{Empiric Antibiotic Therapy in Critically III Febrile Neutropenic Patients with Suspected Bloodstream Infection}

\section{Evidence Statements}

- In a critically ill febrile neutropenic patient presenting to the ICU with organ failure, empiric antibiotic therapy should be initiated or escalated to a broad spectrum carbapenem like imipenem or meropenem (UPP, A).

- Empiric combination of Imipenem or Meropenem and Colistin/Polymyxin B may be considered in the following patients having a high risk of infection with resistant gram-negative organisms (UPP, A):

a. Critically ill patients with underlying acute Leukaemia presenting to the ICU.

b. Patients of Leukaemia/Lymphoma on $\beta$-lactam $/ \beta$ lactamase inhibitor (BL/BLI) \pm aminoglycosides, shifted to ICU from the ward.

c. Previous exposure to broad-spectrum antibiotics like carbapenem or BL/BLI combination in last 1 month.

d. Hypotensive patients requiring vasopressor infusions (refractory septic shock).

e. Patient shifted to the ICU on carbapenem therapy.

- We strongly caution against the use of an empiric combination of Imipenem or Meropenem and Colistin/Polymyxin B or Colistin/Polymyxin B alone in patients who are not a high risk of infection with carbapenem-resistant gram-negative organisms as defined above (UPP, A).

- We recommend against empirical use of Doripenem and Ertapenem (III, A)

- Vancomycin/Teicoplanin should be added as empiric therapy in a critically ill febrile neutropenic patient with

a. Suspected Indwelling vascular catheter infection

b. Skin and soft-tissue infection

c. Previous Colonization/infection with methicillinresistant Staphylococcus aureus (MRSA)

d. Blood Culture: Gram-positive cocci awaiting identification

e. Severe mucositis (III, A)

f. Hemodynamic instability (hypotension) in patients admitted from home /OPD (UPP, A)

- We caution against empirical use of Vancomycin in another group of patients including patients on broad-spectrum antibiotics admitted to the ward and presenting to ICU with hemodynamic instability unless there is a high incidence of MRSA in the institute (UPP, A)

\section{Evidence Summary}

\section{Common isolates in a blood culture in febrile neutropenic patients}

In India, in febrile neutropenic patients, gram-negative bacteremia is much more common than gram-positive bacteremia (Table 2); in contrast to the western data, where gram-positive isolates are more common. ${ }^{5,6}$ The spectrum of bacterial isolates from a number of studies in India suggest Enterobacteriaceae (E. coli and Klebsiella species) and Pseudomonas aeruginosa be the most common among gram-negative organisms. Among gram-positive isolates, Staphylococcus aureus and Coagulase-negative staphylococcus (CoNS) are most common isolates.

There are scarce data regarding the choice of empirical antibiotic regimens in critically ill febrile neutropenic presenting to the Indian ICUs. Most of the studies have a heterogeneous patient population-leukemia, lymphoma, solid, etc. Choice of antibiotics depends on the most likely causative microorganism, local antimicrobial sensitivity patterns, mechanism of action of antimicrobials, and site of infection, patient's predisposing condition and treating physician's judgment. Recent data show an increased prevalence of Multidrug-resistant (MDR) organisms. Several studies in India have shown that the majority of gram-negative bacteria isolated on initial blood cultures from patients were resistant to the non-carbapenem firstline antibiotics. ${ }^{14-17}$ Hence, initial antibiotic choice in a febrile neutropenic patient who is critically ill present- 


\begin{tabular}{|c|c|c|c|c|c|}
\hline Author, year & $\begin{array}{l}\text { No of } \\
\text { isolates }\end{array}$ & $\begin{array}{l}\text { Gm negative } \\
\text { isolates (\%) }\end{array}$ & Common organisms (\%) & $\begin{array}{l}\text { Gram positive } \\
\text { isolates (\%) }\end{array}$ & Common organisms (\%) \\
\hline $\begin{array}{l}\text { Prabhash } \mathrm{K}^{7} \\
2010\end{array}$ & 484 & 68.1 & $\begin{array}{l}\text { Pseudomonas } 30.4, \\
\text { Acinetobacter } 11.6 \\
\text { E coli } 10.9 \\
\text { Klebsiella } 7.3 \\
\text { Enterococcal spp. } 4.1\end{array}$ & 31.9 & $\begin{array}{l}\text { Staph Aureus- } 12.6 \text { (MRSA- 2) } \\
\text { CoNS- } 10.5 \\
\text { Streptococcus spp. } 4.6 \\
\text { Burkholderia spp. } 2.9 \\
\text { Enterobacter spp. } 2.3\end{array}$ \\
\hline $\begin{array}{l}\text { Karanwal et al } \\
2013\end{array}$ & 23 & 78 & $\begin{array}{l}\text { E coli 43, Pseudomonas } \\
17.5\end{array}$ & 22 & $\begin{array}{l}\text { Staph aureus } 22 \\
\text { CoNS- } 4\end{array}$ \\
\hline $\begin{array}{l}\text { Singh et al } \\
2014\end{array}$ & 693 & 74.6 & $\begin{array}{l}\text { E coli } 23.5 \text {, } \\
\text { Pseudomonas } 6.7\end{array}$ & 25.4 & $\begin{array}{l}\text { Staph Aureus- } 34 \text { (MRSA 13) } \\
\text { Enterococcus } 29\end{array}$ \\
\hline $\begin{array}{l}\text { Rajendranath et al }{ }^{10} \\
2014\end{array}$ & 40 & 58.3 & $\begin{array}{l}\text { E coli } 36.7 \text {, } \\
\text { Pseudomonas } 9.2\end{array}$ & 41.7 & $\begin{array}{l}\text { Staph aureus- } 25 \\
\text { (MRSA- 2.5) }\end{array}$ \\
\hline $\begin{array}{l}\text { Sengar et al }{ }^{11} \\
2014\end{array}$ & 739 & 66 & $\begin{array}{l}\text { E coli } 19, \text { Pseudomonas } \\
18.7 \\
\text { Acinetobacter } 7.1 \\
\text { Enterobacter } 4.8\end{array}$ & 34 & $\begin{array}{l}\text { CoNS-20 } \\
\text { Staph aureus- } 5.5 \\
\text { Streptococcus } 3.9 \\
\text { Enterococcus } 3.6\end{array}$ \\
\hline Lakshmaiah et al $^{12}$ & 92 & 61.7 & E coli 36 & 38.3 & Staph Aureus- 36 (MRSA 9) \\
\hline Vivek $B$ et al ${ }^{13}$ & 285 & 63 & $\begin{array}{l}\text { Pseudomonas } 22 \\
\text { E coli } 21.4\end{array}$ & 37 & $\begin{array}{l}\text { CoNS } 12.9 \\
\text { Staph Aureus } 8\end{array}$ \\
\hline
\end{tabular}

ing to the ICU will be carbapenems like Meropenem or Imipenem. The prevalence of carbapenem-resistant gramnegative organisms is alarming at present. According to the Indian Council of Medical Research (ICMR) data on non-neutropenic population, carbapenem resistance among Enterobacteriaceae is 35 to $50 \%$, Pseudomonas spp $47 \%$ and Acinetobacter spp $62 \% .{ }^{17}$ Based on the epidemiology, current evidence and clinical experience the committee has identified risk factors for carbapenem resistance. Particular subgroups of patients, such as acute leukemia patients presenting to the ICU, a patient already

Table 3: Incidence of resistance among common gramnegative bacterial isolates in India (ICMR data) ${ }^{17}$

\begin{tabular}{llllll}
\hline & $\begin{array}{l}E \\
\text { Coli } \\
\text { Antibiotic }\end{array}$ & $\begin{array}{l}\text { Klebsiella } \\
(\%)\end{array}$ & $\begin{array}{l}\text { Entero- } \\
\text { bacter } \\
(\%)\end{array}$ & $\begin{array}{l}\text { Pseudo- } \\
\text { monas } \\
(\%)\end{array}$ & $\begin{array}{l}\text { Acineto- } \\
\text { bacter } \\
(\%)\end{array}$ \\
\hline Amikacin & 24 & 54 & 44 & 35 & 75 \\
Aztreonam & - & - & - & 48 & 87 \\
Cefipime & 79 & 80 & 80 & 41 & 81 \\
Cefaperazone- & 33 & 62 & 39 & 38 & 57 \\
Sulbactam & & & & & \\
Cefotaxime & 80 & 83 & 83 & - & - \\
Ceftazidime & 81 & 84 & 77 & 47 & 84 \\
Ciprofloxacin & 81 & 65 & 48 & - & - \\
Colistin & 1 & 1 & 0 & 10 & 22 \\
Gentamicin & 46 & 65 & 56 & - & - \\
Imipenem & 18 & 35 & 26 & 37 & 63 \\
Levofloxacin & - & - & - & 36 & 73 \\
Meropenem & 35 & 53 & 38 & 47 & 62 \\
Netilmicin & 12 & 42 & 18 & 45 & 69 \\
Piperacillin- & 43 & 68 & 57 & 46 & 83 \\
Tazobactam & & & & & \\
Tetracyclin & 64 & 42 & 16 & - & 55 \\
Tobramycin & - & - & - & 33 & 58 \\
Trimethoprim- & - & - & - & - & 55 \\
Sulpha- & & & & & \\
methoxazole & & & & & \\
\hline & & & & & \\
\hline
\end{tabular}

on carbapenem shifted to ICU from the ward, previous antibiotic exposure in the last 1 month and patients on vasopressors are at risk of harboring carbapenemresistant organisms. ${ }^{18}$ Hence in these groups of patients, initial empiric antibiotic regimen should include colistin/polymyxin B along with Imipenem or Meropenem (Table 3).

Vancomycin is not a standard part of empirical antibiotic therapy for the febrile neutropenic patient. In the western countries with predominant gram-positive bacteremia and high incidence of MRSA, studies have failed to show any benefit with empiric vancomycin in terms of fever or mortality. ${ }^{19}$ In India, with predominant gramnegative sepsis and low incidence of MRSA (35\% as per ICMR data) ${ }_{1}^{17}$ Vancomycin/Teicoplanin is recommended as part of initial antibiotic regimen only in patients with suspected indwelling catheter infection (rigors following infusion, cellulitis at exit site), skin and soft tissue infection, severe mucositis, culture growing gram-positive cocci pending identification, previous MRSA colonization/ infection and hemodynamic instability admitted from home/OPD. ${ }^{7}$

\section{Blood Culture Collection Procedure}

\section{Evidence Statements}

- We recommend a collection of at least two sets of blood cultures, with a set collected simultaneously from a peripheral site and one from the central line. In the case of a multi-lumen catheter, one set per lumen should be collected.

- Two blood culture sets from separate venepunctures should be sent if no central venous catheter is present. 
- One set includes one aerobic and one anaerobic culture bottle. Blood culture volume should be at least $10 \mathrm{~mL} /$ bottle $^{7,20}(\mathrm{I}, \mathrm{A})$.

\section{Evidence Summary}

The volume of blood is an important variable for detection of bloodstream infection volume of blood. Each $\mathrm{ml}$ of blood increased the yield (detection of positive culture) of blood cultures in adults by approximately $3 \%$. Collection of two blood culture sets provide 80 to $90 \%$ yield of bloodstream pathogens in critically ill patients. In the pediatric population, smaller volumes of blood are suggested due to lesser total blood volume. The general consensus is not to exceed $1 \%$ of a patient's total blood volume.

\section{Empiric Antifungal Therapy in Febrile Neutropenic Patient}

\section{Evidence Statements}

Following patients should be considered for initiation of antifungal therapy when they present to ICU with shock or respiratory distress especially when they have a persistent or recurrent fever or clinical deterioration after $>3$ days of broad-spectrum antibiotics (II, A)

a. Allogenic hematopoietic stem cell transplantation (HSCT).

b. Severe mucositis with diarrhea.

c. Prolonged/anticipated duration of neutropenia $>10$ days.

d. Worsening on broad-spectrum antibiotics like BL/ BLI and Carbapenems.

e. More than 3 weeks of steroids.

f. History of invasive fungal infection.

g. New onset lung infiltrates (since chest X-ray has low sensitivity, high-resolution computed tomography (HRCT) should be done in these patients).

- We recommend the use of caspofungin (echinocandin group)as initial antifungal therapy. Caspofungin should be avoided in patients with chronic liver disease (Child-Pugh C.)

- Anidulafungin and Micafungin can be considered if there are contraindications to use of caspofungin.

- Voriconazole is the drug of choice for proven, probable or possible aspergillosis. Due to its variable bioavailability, voriconazole should be administered IV. In patients with renal dysfunction, caspofungin can be given instead of IV voriconazole.

- Liposomal amphotericin B is the drug of choice for suspected or confirmed mucormycosis.

- All efforts should be made to confirm the presence of invasive fungal infection with the use of tests including $\mathrm{CT}$ chest, $\beta$-D-glucan, serum, and bronchoalveolar lavage (BAL) galactomannan, fungal culture. Tissue (lung/other clinically involved sites) biopsy should be performed if required, whenever feasible ${ }^{21-25}$ (II, A).

- We do not recommend the routine use of combination antifungal therapy for probable or proven invasive aspergillosis (III, A).

\section{Evidence Summary}

Invasive Candida or Aspergillus infections have been demonstrated in the autopsy of patients who died of a neutropenic fever with no clinical evidence of invasive fungal infection (IFI) except for a continuous fever. ${ }^{26}$ It is estimated that approximately 15 to $45 \%$ of patients with prolonged neutropenia have an invasive fungal infection (IFI). IFI is difficult to diagnose both in critically ill patients and patients with febrile neutropenia. Invasive fungal infection is associated with high mortality in both these groups especially if treatment is delayed.

High-risk patients who have received intensive cytotoxic chemotherapy are at risk for invasive fungal infection. Yeast (primarily Candida species) and molds typically cause infections, which are manifested by persistent or recurrent fever in patients with prolonged neutropenia, rather than causing initial fever in the course of neutropenia. ${ }^{27,28}$ Empirical antifungal therapy is instituted for the treatment of "occult" fungal infection presenting as persistent neutropenic fever despite 4 to 7 days of empirical antibiotic therapy. ${ }^{29}$

The echinocandins have demonstrated significant fungicidal activity and treatment success against most of the Candida species in randomized clinical trials. Availability of intravenous formulation, limited drug interactions, favorable safety, and efficacy profile make them the first choice of empirical antifungal in critically ill patients including patients with febrile neutropenia. It is generally agreed upon that individual echinocandins namely caspofungin, micafungin and anidulafungin have similar efficacy and are interchangeable. ${ }^{30}$

\section{Recommended Dosage}

- Caspofungin: loading dose of $70 \mathrm{mg}$ followed by $50 \mathrm{mg}$ daily. Dosage reduction is recommended for patients with moderate to severe hepatic dysfunction.

- Micafungin: $100 \mathrm{mg}$ daily. No dose adjustment in the liver or renal failure.

- Anidulafungin: loading dose of $200 \mathrm{mg}$, followed by $100 \mathrm{mg}$ daily. No dose adjustment is required in the liver or renal failure.

Limitations of echinocandin therapy should be kept in mind. Echinocandins have poor penetration in eye, $\mathrm{CNS}$, and urine. Intuitively they should not be used for the treatment of fungal meningitis, endophthalmitis, and urinary tract infection. Echinocandins are not active against Zygomycosis. ${ }^{31}$ 
Echinocandins have activity against Aspergillus species. However, Echinocandins monotherapy as the first line for treatment of Aspergillus is not studied well. Echinocandins have shown to be effective in salvage therapy however they are not recommended as monotherapy for the primary treatment of IA due to lack of evidence. ${ }^{29}$

Lipid formulations of amphotericin B should be used as first-line treatment if Mucormycosis (Zygomycosis) is suspected. The recommended dose is 3 to $5 \mathrm{mg} / \mathrm{kg}$ daily. ${ }^{32}$

Invasive aspergillosis should be suspected in patients with persistent febrile neutropenia with the development of signs of pneumonia including lung infiltrate. Voriconazole can be used for suspected or proven cases of IPA. The dose of Voriconazole is $400 \mathrm{mg}(6 \mathrm{mg} / \mathrm{kg})$ twice daily for two doses, then $\mathrm{mg} / \mathrm{kg}$ ) twice daily. As mentioned above, Echinocandins are recommended for salvage therapy of aspergillosis. ${ }^{33}$

Amphotericin B deoxycholate should be avoided in patients with underlying renal impairment, patients on other nephrotoxic drugs such as cyclosporine or tacrolimus after allogeneic HSCT, or antibiotics, such as aminoglycosides and in patients with previous history of toxicity.

Recommended minimum duration of therapy for candidemia without metastatic complications is 2 weeks after documented clearance of Candida from the bloodstream, provided neutropenia and symptoms attributable to candidemia have resolved. ${ }^{7}$

Investigation for confirmation of invasive fungal infection:

Poor sensitivity of chest radiograph compared to CT scan for detection of pneumonia in this population should be kept in mind. ${ }^{34}$ The galactomannan assay is highly specific for Aspergillus species with some cross-reactivity with Histoplasma capsulatum and Penicillium species. The false positive reaction can occur with concomitant use of b-lactam/b-lactamase combinations, such as piperacillintazobactam. $^{22}$

Marr et al have demonstrated $8.2 \%$ absolute reduction in mortality rates with the combination of voriconazole and anidulafungin in adult patients with hematologic malignancies (HMs) and hematopoietic stem cell transplantation (HSCT) having probable or proven Invasive aspergillosis (IA). However, this difference was not statistically significant.

Combination antifungal treatments are used with the rationale to maximize treatment by targeting multiple sites or metabolic pathways or different steps in the same pathway hence leading to an additive or synergistic effect. While in vitro studies on combination antifungals showed additive or synergistic effect; in vivo studies have given mixed results. While the combinations of azoles with echinocandins has shown additive or synergistic effects; combinations of polyenes with triazoles have demonstrated the antagonistic effect. Lack of in vitro findings has not been replicated with consistency. These in vivo studies are difficult to interpret due to the lack of validated protocols, variable test designs, and a definite end point. Combination antifungal therapy definitely increases the cost of treatment, has the potential to cause deleterious drug interactions, may add toxic effects and have the possibility of increased risk for resistance. In view of the lack of strong evidence in favor as well as potential harmful effects, routine use of a combination of combination antifungal therapy is not recommended. ${ }^{35}$

\section{Empiric Antiviral Therapy in Febrile Neutropenic Patient}

\section{Evidence Statements}

- There is no role of empirical antiviral therapy with febrile neutropenia (III, A)

- Acyclovir is recommended for the treatment of Varicella-Zoster virus (VZV) or Herpes Simplex virus (HSV) infection in the presence of clinical or laboratory evidence of infection is present (III, B)

- Serological (Immunoglobulin) tests should not be used to diagnose VZV or HSV infection (III, A) 36-39 $^{39}$

- Ganciclovir is recommended for the empiric therapy for Cytomegalovirus (CMV) in below-mentioned patients with high risk of CMV reactivation if they present with diarrhea/pneumonia not responding to antibiotics and antifungals (UPP, A)

a. Patients on T-cell-depleting agents such as fludarabine/purine analogs as well as rituximab

b. Patients on high dose steroids who develop diarrhea

c. Pneumonia not responding to antibiotics and antifungals

\section{Evidence Summary}

General consensus does not recommend the empirical use of antiviral drugs in the management of febrile neutropenic patients except in cases with clinical or laboratory evidence of viral infection. Cellular immunity offered by $\mathrm{T}$ cells helps in controlling CMV replication preventing its recurrence hence patients receiving T-cell-depleting agents are at risk of CMV reactivation. No specific treatment for infections with RSV and parainfluenza viruses is recommended due to the lack of specific evidence. $^{40,41}$ 


\section{Empiric Treatment Against Pneumocystis Carinii/ Jiroveci Pneumonia (PCP) in febrile neutropenic patient}

\section{Evidence Statements}

- Treatment with sulfamethoxazole/trimethoprim should be considered in high-risk patients such as allogeneic HSCT, high-dose corticosteroid therapy administration of T-cell-depleting agents such as fludarabine/purine analogs and rituximab when such patients present with hypoxemic respiratory failure with or without radiological evidence of pneumocystis carinii pneumonia especially if they are not on PCP prophylaxis (III, A)

- Every attempt should be made to confirm PCP infection $(\mathrm{I}, \mathrm{A})$

\section{Evidence Summary}

Patients considered high risk for PCP infection are allogeneic HSCT recipients (Good evidence), autologous HSCT, high-dose corticosteroid therapy and patients receiving T-cell-depleting agents such as fludarabine, purine analogs and rituximab (moderate evidence). ${ }^{42-44}$ If they present with hypoxemic respiratory failure, then such patients should be on sulfamethoxazole/trimethoprim. Hypoxemia is the most characteristic abnormality in PCP pneumonia. Chest radiograph might be normal in early disease.

\section{Role for Empiric Antimicrobial Therapy for Tropical Infections like Malaria, Leptospirosis}

\section{Evidence Statements}

- There is no role for empirical antimicrobial therapy against tropical infections like malaria, leptospirosis (III, A)

- Documented tropical infections in neutropenic patients in ICU should be treated similarly as they are treated in non-neutropenic patients (UPP, B)

\section{Evidence Summary}

There are occasional reports of malaria in patients on chemotherapy with a solid tumor and hematolymphoid malignancies with febrile neutropenia. In a series of 99 patients of acute leukemia on chemotherapy with febrile neutropenia, malaria was responsible for fever in only $4 \%$ of patients. ${ }^{45}$

Febrile neutropenia patient presenting to ICU often have thrombocytopenia due to the disease itself, chemotherapy or sepsis. Presence of fever and thrombocytopenia itself should not warrant empirical anti-malarial therapy even in a malaria-endemic country like India.
A high index of suspicion is warranted in a resident or traveler of malaria endemic area who presents with the classic triad of symptoms (fever, chills, and sweating). If malaria is suspected, peripheral smear for malaria parasite and rapid malaria antigen [e.g. Histidine-rich protein II (HRP-II) antigen of Plasmodium falciparum and common Plasmodium lactate dehydrogenase $(\mathrm{pLDH})$ of Plasmodium species] should be performed early, and antimalarial therapy should be initiated in positive cases. With rapidity (diagnosis in less than an hour) and good negative predictive value of $(98.2 \%)$ malaria antigen test, antimalarial therapy is restricted only to positive cases. $^{46}$

There is lack of enough evidence documenting the etiological role of other tropical infections like Leptospirosis in a subset of patients with febrile neutropenia; hence we believe that until enough evidence is available, suspected or documented tropical infections in neutropenic patients in ICU should be treated similarly as they are treated in non-neutropenic patients.

\section{Role of Surveillance Cultures}

\section{Evidence Statement}

- We strongly recommend against repeated surveillance cultures as these do not help to guide antibiotic therapy (III, A)

\section{Evidence Summary}

As most of the infections in neutropenic patients occur due to organisms in the respiratory or gastrointestinal tract, therefore surveillance culture seems to be a reasonable strategy in deciding the empiric antibiotic therapy in febrile neutropenia. The studies published in the 1980s and '90s supported the practice of surveillance culture. However, there has been a very poor correlation between blood and fecal isolates in most of the studies. ${ }^{47,48}$

Widespread antimicrobial treatment may inhibit the growth or distort the proportion of different species found in fecal cultures. A recent study conducted in pediatric allogeneic HSCT patients has demonstrated a positive predictive value of $0.9 \%$ to bacterial surveillance cultures, with a sensitivity of $33.3 \%$ and a specificity of $47.4 \%$. Surveillance cultures were not cost effective. The sampling and analyses require lots of laboratory and nursing resources. ${ }^{49}$ Another study in adults who got admitted for HSCT concluded that surveillance blood cultures in patients who have undergone HSCT do not identify bloodstream infections. The number of positive blood cultures was not helpful in determining which patients had an infection. ${ }^{50}$ 


\section{Role of Source Control in the Treatment of a Febrile Neutropenic Patient}

\section{Evidence Statements}

- We recommend that in patients with febrile neutropenia with a clinically documented source of infection; immediate intervention should be undertaken for source control (III, A)

- We recommend that Non-tunnelled (short term) central venous catheter $(\mathrm{CVC})$ should be promptly removed in following cases (III, A). ${ }^{52}$

a. CVC is an obvious source of infection.

b. Patient not improving/deteriorating in spite of 24 hours of antibiotics and resuscitation with no other source of infection evident

- We recommend that long term central venous catheter should be promptly removed in presence of any of the following (III, A). ${ }^{52}$

a. Documented line/blood infection with S. aureus, or Candida species

b. Tunnel infection or port abscess

c. Septic thrombosis, endocarditis or osteomyelitis

- We suggest considering the removal of long term central venous catheter in the absence of abovementioned features if there is deterioration or no improvement in patients condition and no other obvious source of infection is evident (UPP, B)

\section{Evidence Summary}

Control of source in the form of drainage of an abscess, debridement of infected necrotic tissue and removal of a potentially infected device is of paramount importance. Foci of infection readily amenable to source control include but not limited to intra-abdominal abscesses, gastrointestinal perforation, ischaemic bowel or volvulus, cholangitis, cholecystitis, pyelonephritis associated with obstruction or abscess, necrotizing soft tissue infection, empyema, septic arthritis, and implanted device infections. There is general agreement that source control should be done at the earliest to reduce microbiological burden, and mere antibiotics and resuscitation would not achieve cure unless adequate source control is done. If Vascular catheters are suspected, its prompt removal should be considered. It is important to note that the classical clinical signs of infection (rubor, calor, dolor, etc) be absent due to low neutrophil counts. ${ }^{51}$

Patients with S. aureus catheter-related bloodstream infection (CRBSI) have a significantly higher risk of hematogenous complications with the retained foreign body, especially in immunocompromised patients. Retention of the catheter has shown to worsen the outcome of candidaemia. ${ }^{52}$

\section{Antibiotics De-escalation}

\section{Recommendations}

- Antimicrobial de-escalation should be implemented in the following situations: (III, A)

a. Once and if a pathogen is identified, we recommend de-escalation to an antibiotic that the organism is susceptible to.

b. We recommend treating with appropriate agents based on the site and pathogen until the patient is afebrile for at least 48 hours and there is evidence of marrow recovery (neutrophil count $\geq 500$ cells / $\mathrm{mm}^{3}$ ).

c. In patients without microbiologically documented infection we recommend continuing empirical antimicrobials until the patient is afebrile for at least 48 hours and there is evidence of marrow recovery (neutrophil count $\geq 500$ cells $/ \mathrm{mm}^{3}$ )

\section{Evidence Summary}

Data on de-escalation strategies in neutropenic patients after identification of a clinically relevant pathogen is scant, and there is no data on de-escalation when no pathogen has been identified. Although antibiotics are required to treat an occult infection during neutropenia, marrow recovery is necessary to protect the patient. ${ }^{18}$

\section{Antibiotics for Multidrug-resistant Bacteria Useful Practice Points}

Antibiotics like Fosfomycin, tigecycline and minocycline may be considered in infection with multidrug-resistant bacteria in the presence of in vitro susceptibility after considering the in vivo penetration at the source of sepsis.

\section{Evidence Summary}

\begin{tabular}{llll}
\hline & Fosfomycin & Tigecycline & Minocycline \\
\hline Good & E. coli, Citrobacter & Most Entero- & Most Entero- \\
activity & sp, Proteus & bacteriaceae, & bacteriaceae, \\
& mirabilis, & Acinetobacter & Acinetobacter \\
& Streptococcus sp, & sp, Staphy- & sp, \\
& Staphylococcus & lococcus & Staphylococcus \\
& aureus (MSSA & aureus & aureus (MSSA, \\
& and MRSA) and & (MSSA, & MRSA), \\
& Enterococcus & MRSA), & Enterococcus \\
& faecalis & Enterococcus & sp (VRE) and \\
& & sp (VRE) and & anaerobes \\
Poor & Pseudomonas sp, & Pseudomonas & Pseudomonas \\
activity & Acinetobacter sp, & sp, Proteus & sp, Proteus sp, \\
Bacteroidesspp & sp, & Providencia sp \\
(Anaerobes), & Providencia & and Morganella \\
Coagulase negative & sp and & sp. \\
staphylococcus, & Morganella sp. & \\
Morganella- & & \\
morganii and & & \\
Enterococcus & & \\
faecium & & \\
\hline
\end{tabular}




\begin{tabular}{|c|c|c|c|}
\hline Uses & $\begin{array}{l}\text { Bacteraemia, } \\
\text { VAP, UTI, wound } \\
\text { infection and } \\
\text { meningitis }\end{array}$ & $\begin{array}{l}\text { Skin and soft } \\
\text { tissue infection } \\
\text { and intra- } \\
\text { abdominal } \\
\text { infection }\end{array}$ & $\begin{array}{l}\text { Ventilator - } \\
\text { associated } \\
\text { pneumonia } \\
\text { (VAP) } \\
\text { urinary tract } \\
\text { infections (UTI) } \\
\text { Hospital/ } \\
\text { healthcare } \\
\text {-Acquired } \\
\text { Pneumonia } \\
\text { (HAP) }\end{array}$ \\
\hline Caution & High sodium load & $\begin{array}{l}\text { Should not } \\
\text { be used as a } \\
\text { sole agent in } \\
\text { Bacteriamia, } \\
\text { pnuemonia }\end{array}$ & \\
\hline
\end{tabular}

VAP: Ventilator Associated Pneumonia

HAP: Hospital/healthcare Acquired Pneumonia

Urinary Tract Infections (UTI)

\section{REFERENCES}

1. Darmon M, Azoulay E. Critical care management of cancer patients: cause for optimism and need for objectivity. Current opinion in oncology. 2009;21:318-326.

2. Namendys-Silva SA, Plata-Menchaca EP, Rivero-Sigarroa E, Herrera-Gómez A. Opening the doors of the intensive care unit to cancer patients: a current perspective. World journal of critical care medicine. 2015;4:159-162

3. Jindal AK, Pilania RK, Rawat A, Singh S. Primary immunodeficiency Disorders in india-A situational review. Frontiers in immunology. 2017;8:714.

4. Klastersky J, De Naurois J, Rolston K, Rapoport B, Maschmeyer G, Aapro M, Herrstedt J. Management of febrile neutropaenia: ESMO clinical practice guidelines. Annals of Oncology. 2016;27(suppl_5):v111-118.

5. Wisplinghoff $\mathrm{H}$, Seifert H, Wenzel RP, Edmond MB. Current trends in the epidemiology of nosocomial bloodstream infections in patients with hematological malignancies and solid neoplasms in hospitals in the United States. Clinical Infectious Diseases. 2003;36:1103-1110.

6. Freifeld AG, Bow EJ, Sepkowitz KA, Boeckh MJ, Ito JI, Mullen CA, Raad II, Rolston KV, Young JA, Wingard JR. Clinical practice guideline for the use of antimicrobial agents in neutropenic patients with cancer: 2010 update by the Infectious Diseases Society of America. Clinical infectious diseases. 2011;52:e56-93.

7. Prabhash K, Medhekar A, Ghadyalpatil N, Noronha V, Biswas S, Kurkure P, Nair R, Kelkar R. Blood stream infections in cancer patients: A single center experience of isolates and sensitivity pattern. Indian journal of cancer. 2010;47:184-188.

8. Karanwal AB, Parikh BJ, Goswami P, Panchal HP, Parekh BB, Patel KB. Review of clinical profile and bacterial spectrum and sensitivity patterns of pathogens in febrile neutropenic patients in hematological malignancies: A retrospective analysis from a single center. Indian journal of medical and paediatric oncology: official journal of Indian Society of Medical \& Paediatric Oncology. 2013;34:85-88.

9. Singh R, Jain S, Chabbra R, Naithani R, Upadhyay A, Walia M. Characterization and anti-microbial susceptibility of bacterial isolates: Experience from a tertiary care cancer center in Delhi. Indian journal of cancer. 2014;51:477-80.

10. Rajendranath R, Balasubramaniyum VK, Vijayakumar V, Ganesan P, Tenali GS. Factors predicting outcome in high risk febrile neutropenia in patients receiving intensive chemotherapy for acute sleukemia: A prospective, observational study from South India. Indian journal of cancer. 2014;51:481486.

11. Sengar M, Kelkar R, Jain H, Biswas S, Pawaskar P, Karpe A. Frequency of bacterial isolates and pattern of antimicrobial resistance in patients with hematological malignancies: A snapshot from tertiary cancer center. Indian journal of cancer. 2014;51:456-458.

12. Lakshmaiah KC, Abhayakumar SM, Shetty R, Loknath D, Jayashree RS, Govindbabu K. Management of febrile neutropenia in solid organ malignancies following chemotherapy. Journal of cancer research and therapeutics. 2014;10:540543.

13. Bhat V, Gupta S, Kelkar R, Biswas S, Khattry N, Moiyadi A, et al. Bacteriological profile and antibiotic susceptibility patterns of clinical isolates in a tertiary care cancer center. Indian journal of medical and paediatric oncology: official journal of Indian Society of Medical \& Paediatric Oncology. 2016;37:2024.

14. Laxminarayan R, Chaudhury RR. Antibiotic resistance in India: drivers and opportunities for action. PLoS medicine. 2016;13:e1001974.

15. Sood S, Gupta R. Antibiotic resistance pattern of community acquired uropathogens at a tertiary care hospital in Jaipur, Rajasthan. Indian journal of community medicine: official publication of Indian Association of Preventive \& Social Medicine. 2012;37:39-44.

16. Kakkar M, Walia K, Vong S, Chatterjee P, Sharma A. Antibiotic resistance and its containment in India. BMJ. 2017;358:j2687.

17. Treatment guidelines for antimicrobial use in common syndromes. Indian Council of Medical Research, department of health research, Delhi, India. https: / / www.icmr.nic.in/sites/ default/files/guidelines/treatment_guidelines_for_antimicrobial.pdf/last accessed on 25th December 2018.

18. Averbuch D, Orasch C, Cordonnier C, Livermore DM, Mikulska M, Viscoli C, et al. European guidelines for empirical antibacterial therapy for febrile neutropenic patients in the era of growing resistance: summary of the 2011 4th European Conference on Infections in Leukemia. haematologica. 2013;98:1826-1835.

19. Paul M, Borok S, Fraser A, Vidal L, Leibovici L. Empirical antibiotics against Gram-positive infections for febrile neutropenia: systematic review and meta-analysis of randomized controlled trials. Journal of Antimicrobial Chemotherapy. 2005;55:436-444.

20. Mermel LA, Maki DG. Detection of bacteremia in adults: consequences of culturing an inadequate volume of blood. Annals of internal medicine. 1993 Aug 15;119(4):270-272.

21. Song KH, Lee S, Jang HC, Jeon JH, Park WB, Park KU, et al. Diagnostic usefulness of galactomannan assay for invasive aspergillosis. Infection and Chemotherapy. 2009;41:8289.

22. Maertens J, Theunissen K, Verhoef G, Verschakelen J, Lagrou $\mathrm{K}$, Verbeken E, et al. Galactomannan and computed tomography-based preemptive antifungal therapy in neutropenic patients at high risk for invasive fungal infection: a prospective feasibility study. Clinical infectious diseases. 2005;41:12421250.

23. Odabasi Z, Mattiuzzi G, Estey E, Kantarjian H, Saeki F, Ridge $\mathrm{RJ}$, et al. -D-glucan as a diagnostic adjunct for invasive fungal infections: validation, cutoff development, and performance in patients with acute myelogenous leukemia and myelo- 
dysplastic syndrome. Clinical Infectious Diseases. 2004 Jul 15;39(2):199-205.

24. Ostrosky-Zeichner L, Alexander BD, Kett DH, Vazquez J, Pappas PG, Saeki F, et al. Multicenter clinical evaluation of the (1 3) -D-glucan assay as an aid to diagnosis of fungal infections in humans. Clinical Infectious Diseases. 2005;41:654-659.

25. Senn L, Robinson JO, Schmidt S, Knaup M, Asahi N, Satomura S, et al. 1, 3- -D-glucan antigenemia for early diagnosis of invasive fungal infections in neutropenic patients with acute leukemia. Clinical Infectious Diseases. 2008;46:878-885.

26. Bodey G, Bueltmann B, Duguid W, Gibbs D, Hanak H, Hotchi $M$, et al. Fungal infections in cancer patients: an international autopsy survey. European Journal of Clinical Microbiology and Infectious Diseases. 1992;11:99-109.

27. Gerson SL, Talbot GH, Hurwitz S, Strom BL, Lusk EJ, Cassileth PA. Prolonged granulocytopenia: the major risk factor for invasive pulmonary aspergillosis in patients with acute leukemia. Annals of internal medicine. 1984;100:345-51.

28. Pagano L, Caira M, Candoni A, Offidani M, Fianchi L, Martino B, Pastore D, Picardi M, Bonini A, Chierichini A, Fanci R. The epidemiology of fungal infections in patients with hematologic malignancies: the SEIFEM-2004 study. Haematologica. 2006;91:1068-1075.

29. Goldberg E, Gafter-Gvili A, Robenshtok E, Leibovici L, Paul M. Empirical antifungal therapy for patients with neutropenia and persistent fever: systematic review and meta-analysis.EuropeanJournalofCancer.2008Oct1;44(15):2192203.

30. Lee DG, Kim SH, Kim SY, Kim CJ, Min CK, Park WB, et al. Evidence-based guidelines for empirical therapy of neutropenic fever in Korea. Infection \& Chemotherapy. 2011;43:285-321.

31. Eschenauer G, DePestel DD, Carver PL. Comparison of echinocandin antifungals. Therapeutics and clinical risk management. 2007;3:71-97.

32. McCarthy M, Rosengart A, Schuetz AN, Kontoyiannis DP, Walsh TJ. Mold infections of the central nervous system. New England Journal of Medicine. 2014;371:150-160.

33. Walsh TJ, Pappas P, Winston DJ, Lazarus HM, Petersen F, Raffalli J, et al. Voriconazole compared with liposomal amphotericin B for empirical antifungal therapy in patients with neutropenia and persistent fever. New England Journal of Medicine. 2002;346:225-234.

34. Heussel CP, Kauczor HU, Heussel GE, Fischer B, Begrich $\mathrm{M}$, Mildenberger $\mathrm{P}$, et al. Pneumonia in febrile neutropenic patients and in bone marrow and blood stem-cell transplant recipients: use of high-resolution computed tomography. Journal of Clinical Oncology. 1999;17:796-805.

35. Marr KA, Schlamm HT, Herbrecht R, Rottinghaus ST, Bow EJ, Cornely OA, et al. Combination antifungal therapy for invasive aspergillosis: a randomized trial. Annals of internal medicine. 2015;162:81-89.

36. Leung J, Harpaz R, Baughman AL, Heath K, Loparev V, Vázquez M, et al. Evaluation of laboratory methods for diagnosis of varicella. Clinical infectious diseases. 2010;51:23-32.

37. Frisch S, Guo AM. Diagnostic methods and management strategies of herpes simplex and herpes zoster infections. Clinics in geriatric medicine. 2013;29:501-526.

38. Anderson NW, Buchan BW, Ledeboer NA. Light Microscopy, Culture, Molecular, and Serologic Methods for Detection of Herpes Simplex Virus. Journal of Clinical Microbiology. American Society for Microbiology; 2013;52:2-8.

39. Leland DS, Ginocchio CC. Role of cell culture for virus detection in the age of technology. Clinical microbiology reviews. 2007;20:49-78.
40. Nichols WG, Corey L, Gooley T, Davis C, Boeckh M. Parainfluenza virus infections after hematopoietic stem cell transplantation: risk factors, response to antiviral therapy, and effect on transplant outcome. Blood. 2001;98:573-578.

41. Small TN, Casson A, Malak SF, Boulad F, Kiehn TE, Stiles J, Ushay HM, Sepkowitz KA. Respiratory syncytial virus infection following hematopoietic stem cell transplantation. Bone marrow transplantation. 2002;29:321-327.

42. Martin-Garrido I, Carmona EM, Specks U, Limper AH. Pneumocystis pneumonia in patients treated with rituximab. Chest. 2013;144:258-265.

43. Byrd JC, Hargis JB, Kester KE, Hospenthal DR, Knutson SW, Diehl LF. Opportunistic pulmonary infections with fludarabine in previously treated patients with low grade lymphoid malignancies: a role for Pneumocystis carinii pneumonia prophylaxis. American journal of hematology. 1995;49:135142.

44. Roblot F, Imbert S, Godet C, Kauffmann C, Ragot S, Moal GL, et al. Risk factors analysis for Pneumocystis jiroveci pneumonia (PCP) in patients with haematological malignancies and pneumonia. Scandinavian journal of infectious diseases. 2004;36:848-854.

45. Noronha V, Goyal G, Joshi A, Gupta S, Ghosh J, Bajpai J, et al. Presentation, complications, and impact of concurrent malaria infection on anticancer therapy. Indian journal of cancer. 2013;50:254-260.

46. Advani SH, Banavali SD. Pattern of infection in hematologic malignancies: an Indian experience. Reviews of infectious diseases. 1989; 11 Suppl 7:S1621-1628.

47. Wells CL, Ferrieri P, Weisdorf DJ, Rhame FS. The importance of surveillance stool cultures during periods of severe neutropenia. Infection Control \& Hospital Epidemiology. 1987;8:317319.

48. Cohen ML, Murphy MT, Counts GW, Buckner CD, Clift RA, Meyers JD. Prediction by surveillance cultures of bacteremia among neutropenic patients treated in a protective environment. Journal of Infectious Diseases. 1983;147:789793.

49. Simojoki ST, Kirjavainen V, Rahiala J, Kanerva J. Surveillance cultures in pediatric allogeneic hematopoietic stem cell transplantation. Pediatric transplantation. 2014;18:87-93.

50. Ghazal SS, Stevens MP, Bearman GM, Edmond MB. Utility of surveillance blood cultures in patients undergoing hematopoietic stem cell transplantation. Antimicrobial resistance and infection control. 2014;3:20.

51. Rhodes A, Evans LE, Alhazzani W, Levy MM, Antonelli M, Ferrer R, et al. Surviving Sepsis Campaign: International Guidelines for Management of Sepsis and Septic Shock 2016. Intensive Care Med 2017;45:486-552

52. Mermel LA, Allon M, Bouza E, Craven DE, Flynn P, O'grady $\mathrm{NP}$, et al. Clinical practice guidelines for the diagnosis and management of intravascular catheter-related infection: 2009 Update by the Infectious Diseases Society of America. Clinical infectious diseases. 2009;49:1-45.

53. Fowler Jr VG, Justice A, Moore C, Benjamin Jr DK, Woods CW, Campbell S, et al. Risk Factors For Hematogenous Complications of Intravascular Catheter-Associated Staphylococcus aureus Bacteremia. Clinical infectious diseases. 2005;40:695703. 


\section{SOLID ORGAN TRANSPLANT (SOT) RECIPI- ENT IN THE INTENSIVE CARE UNIT (ICU)}

Infectious complications in solid organ transplant (SOT) recipients pose unique challenges when such patients require intensive care unit (ICU) care. The net immunological state of these patients is a measure of an individual's unique susceptibility to infection and incorporates an assessment of several important contributing factors.

- Pretransplant diagnosis or treatment

- Nature of organ transplant received (e.g., lung vs. liver organ transplant)

- Dose, duration, and choice of maintenance immunosuppression

- Comorbidities (e.g., viral coinfection [hepatitis C virus (HCV), cytomegalovirus (CMV)], malnutrition, end-organ failure [cirrhosis, chronic kidney disease])

- Breaches of the mucocutaneous barrier: Indwelling devices, mucositis

Detection of infection in SOT recipients is difficult and requires a high index of suspicion, as fever and localizing signs are usually absent in the majority of the patients. Detection of infections should include an assessment of risk factors, detailed history, and physical examination. The infections in SOT patients can be categorized as follows.

- C-Community-acquired

- R-Reactivation

- E-Epidemiologic exposure

- D-Donor-derived

- I-Iatrogenic

- T-Travel related

It is advisable to have a syndrome-based approach (e.g., Nonspecific febrile illness, pneumonia, urinary tract, central nervous system) at first and then narrow the differential diagnoses of possible organisms that could cause the clinical presentation(s).

Microbiological diagnosis is crucial in this patient group. In the context of extensive differential diagnoses, the value of early and specific diagnostics with the use of invasive procedures if necessary (bronchoscopy, tissue biopsy, or aspiration of collections) to obtain specimens cannot be underestimated. After transplantation, serologic techniques are of limited use because transplant recipients may not mount timely serologic responses.

Table 1: Timeline of infections after a solid organ transplant

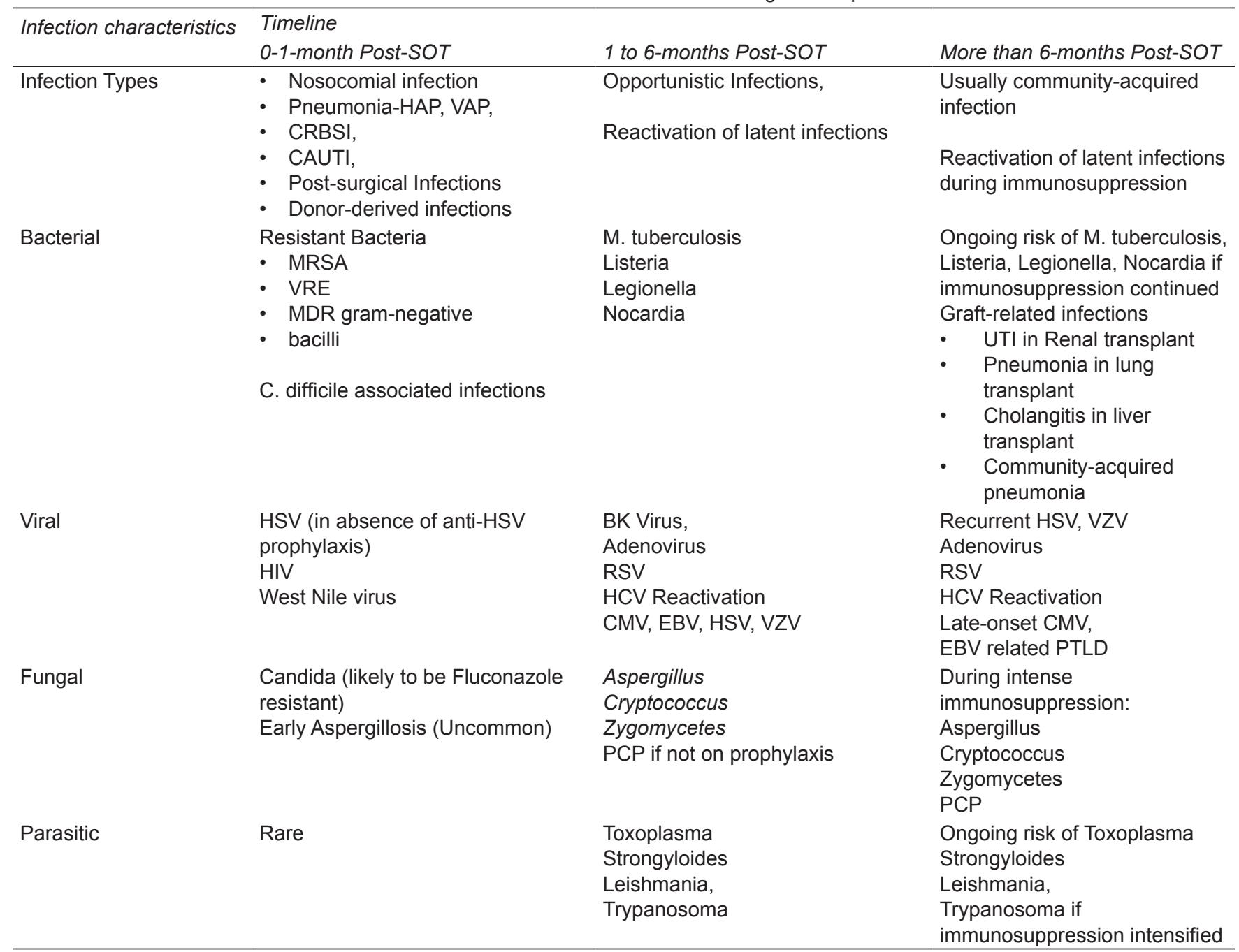


Thus, antigen detection or molecular nucleic acid detection assays are preferred over serologic testing.

The timeline of post-transplant infections reflects the post-transplantation relationship between the recipient's epidemiologic exposures and immunosuppressive strategy employed (Table 1). It is used to establish a differential diagnosis for infectious syndromes at various stages after transplantation. Infections occurring outside the usual period or of unusual severity suggest excessive immunosuppression or epidemiologic hazard. Most centers use a variation of standard 'triple immunosuppression' (prednisone, calcineurin inhibitor, antimetabolite such as mycophenolate mofetil).

\section{Evidence Statements}

- Infections in the first month (0-30 days) of post SOT period should be treated similarly to the treatment of a non-immunocompromised postoperative patient (I, A).

Approach to initial diagnostic workup and empiric therapy in post SOT recipients (30-180 days).

- We recommend early BAL in patients with suspected pneumonia coming to ICU (I, A). We recommend that the BAL fluid should be tested for (I, A).

Total and differential cell counts

Microbiology

- Cultures: Aerobic culture for bacteria, mycobacterial growth indicator tube (MGIT) for mycobacterium tuberculosis, fungal culture

- Stains and immunohistochemistry

Gram stain: Bacterial

KOH preparation/Calcofluor white: Fungal

Auramine-rhodamine, auramine-o, or ziehl-neelson: Mycobacterial

Modified acid-fast stain (kinyoun): Nocardia

Silver methenamine: Pneumocystis carinii pneumonia, fungal

- Galactomannan assay: Negative predictive value $<0.5$, positive predictive value $>3$

a Polymerase chain reaction (PCR)

Mycobacterium tuberculosis: Cartridge Based Nucleic Acid Amplification Test (CB-NAAT or GeneXpert)

Multiplex PCR assay

口 Quantitative or semiquantitative cultures particularly for pneumonia.

Following organisms are diagnostic of infections. If organisms are identified it is less likely to be the contaminants/colonizers and should be treated.

- Pneumocystis carinii

- Toxoplasma gondii

- Strongyloides stercoralis

- Legionella pneumophila
- Cryptococcus neoformans

- Histoplasma capsulatum

- Mycobacterium tuberculosis

- Mycoplasma pneumoniae

- Influenza a and b viruses

- Respiratory syncytial virus

- Cytology

- We recommend HRCT chest for the diagnosis of nodular infiltrates to rule out invasive aspergillosis (I, A).

- We recommend empiric management with carbapenem and azithromycin till causative organisms are identified (I, A).

- We recommend adding polymyxins if the patient is admitted with $\geq 48$ hours before symptoms (I, A)

Medical care (hemodialysis, wound care, immunosuppressants) within the previous 30 days (UPP, B)

Hospitalization in an acute care hospital $\geq 2$ days within the prior 90 days (UPP, B)

- We recommend voriconazole in the dose of $6 \mathrm{mg} / \mathrm{kg}$ bd for 1-day f/b 3mg/kg bd (I, A)

- As a salvage therapy, we recommend Caspofungin (dose $70 \mathrm{mg}$ IV followed by $50 \mathrm{mg}$ iv daily) (I, A)

- We recommend therapeutic drug level monitoring of the voriconazole when using these agents for the treatment of Invasive Aspergillosis (I, A).

\section{Evidence Summary}

During the first month after SOT, opportunistic infections are generally absent as the full effect of immunosuppression has not yet been established. In this period donorderived or recipient-derived viremia, candidemia or technical complications related to surgery are common. ${ }^{1}$ Most infections are caused by gram-negative bacterial (GNB). Bacterial infections are either nosocomial or healthcare-associated ( $27.4 \%$ and $49.8 \%$ respectively); the remaining $22.9 \%$ are community-acquired. ${ }^{2}$ The urinary tract infection (UTI) is the most common primary source of GNB infections in 55.2\% of SOT recipients. Gastrointestinal infections are the second most common infections $(15.2 \%)$. Other infections include infections of the respiratory tract $(3.6 \%)$, intravascular catheters (3.6\%) and skin and soft tissue $(2.7 \%)$ are also seen in SOT recipients in decreasing order of occurrence. E. coli has been found to be the most common GNB (36.8\%), followed by K. pneumoniae $(14.3 \%)$, P. aeruginosa (13.0\%), Enterobacter cloacae (4.9\%) and Citrobacter freundii $(4.5 \%)$ whereas polymicrobial infections occurred in $8.1 \%$ of cases. The incidence of GNB infections shows a declining trend to fall to 25.7 (95\% CI: 20.1-32.1)from 2 to 12 months. It further declines to 8.2 (95\% CI: 6.7-10.0) after 12 months per 1000 personyears following SOT. ${ }^{1,2}$ 
Indian Antimicrobial Prescription Guidelines in Critically III Immunocompromised Patients

Table 2: Common infections in SOT recipients in the period 30 to 180 days $1-41$

\begin{tabular}{lllll}
\hline Bacterial infections & & Viral infections & $\begin{array}{l}\text { Mycobacterial } \\
\text { infections }\end{array}$ & Fungal infections \\
\hline Community-acquired & Nosocomial & Respiratory viruses: & Tuberculosis & Invasive moulds: \\
pathogens: & pathogens & Influenza, Parainfluenza, & Nontuberculous mycobacteria: Aspergillus, \\
S pneumoniae, & Gram-negative & RSV, Human & mycobacterium avium complex Zygomycetes, \\
H influenzae, & bacilli (E. coli, P. & metapneumovirus, & (MAC), M. abscessus & Fusarium, \\
$M$ catarrhalis, & aeruginosa, K. & Adenovirus, & Scedosporium \\
S aureus, & pneumoniae), & Coronavirus, entero/ & Pjirovecii pneumonia \\
Mycoplasma & MRSA, Legionella & Rhinovirus & (PJP/PCP) \\
pneumoniae, & Clostridiumdifficile & CMV, Herpes simplex & Cryptococcus \\
Chlamydia pneumoniae & & virus (HSV), Varicella- & (neoformans) \\
Nocardia rhodococus & & zoster virus (VZV) & Endemic mycoses: \\
& & & Histoplasmosis, \\
& & & Coccidiomycosis, \\
\end{tabular}

Indian data shows that UTI is the most common infection. ${ }^{3}$ In 169 renal allograft recipients, they observed that $23.6 \%$ of the SOT recipients develop UTI during first 4 weeks and E. coli is the most common causative agent $(12.6 \%)$. CMV is the most common (prevalence of CMV 21.8\%) between 4 weeks to 3 months after renal transplantation and can cause allograft loss. Tuberculosis reactivated commonly between 3 months to 1-year post-transplant (prevalence of tuberculosis being $10.6 \%$ ). Pneumocystis carinii and Aspergillus are serious hazards which usually occur after 1 year. Aspergillus infection is the leading fungal infection $(10.0 \%){ }^{3}$ Another retrospective study in of 144 renal transplant patients also found that UTI was the most common infection (34.5\%), followed by viral $(31.2 \%)$, sepsis $(15.2 \%)$, mycobacterial $(9.7 \%)$ and fungal (6.2\%). Parasitic infections (giardiasis and Strongyloides hyper infection syndrome) occurred in $2(1.4 \%)$ patients. CMV accounted for $14.5 \%$ and $B K$ virus (Polyomavirus hominis1) for $5.5 \%$ of total infections. ${ }^{4}$ One prospective observational study in 45 renal transplant recipients reported a similar finding. In the same study, other infections like tuberculosis $(n=8), \operatorname{CMV}(n=6)$, candidiasis $(n=7)$, hepatitis $(n=11)$, cryptosporidiosis and pneumocystis $(\mathrm{n}=10)$ and in 7 patients simultaneous infections with two organisms were seen. E. coli (33.3\%) was the most common organism grown in culture followed by Klebsiella (20\%), Acinetobacter $(20 \%)$, Proteus (6.67\%), and others such as Staphylococcus or Pseudomonas (6.67\%). The incidence of MDR was found to be $31.8 \%{ }^{5}$

A study on bacterial infections in SOT recipients in liver transplant recipients observed that overall incidence of infections during the first-month post-transplant was $80.2 \%$ and the incidence of bacterial pneumonia in the first six months was $21.3 \%(101 / 475)$. A prospective study of 475 liver transplant recipients found that the frequent pneumonia isolates were Enterobacteriaceae, Acinetobacter baumannii, P. aeruginosa and Staphylococcus aureus. Gramnegative bacilli accounted for $69.6 \%$ of all pneumonia pathogens out of which MDR rate was 58.9\%. ${ }^{6}$
One prospective multicenter study involving 35 centers reported the incidence of pneumonia after SOT as 10.1 episodes/1000 recipients/year and bacteria $(87.1 \%)$, virus (29\%), and fungi (6.4\%) were the common causative agents. A multidrug-resistant bacterium is isolated in $18.2 \%, 40 \%$, and $100 \%$ of patients with CAP, $\operatorname{HCAP}$, and HAP ( $\mathrm{p}=0.007)$, respectively. Overall, $11.1 \%$ of patients admitted to the intensive care unit, 3.7\% developed graft rejection, and graft function deteriorated in $18.5 \%$. In-hospital mortality was $1.9 \%{ }^{7}$ In renal transplant recipients, bacterial infections are the most common cause of pneumonia. A retrospective study of 406 renal transplant recipients observed that incidence of healthcare-associated pneumonia is $56 \%$ and bacterial infections are the most common cause $(31 \%$ of the patients), especially haemophilus influenzae, stenotrophomonas maltophilia, and pseudomonas aeruginosa. ${ }^{8}$ Another prospective study of 610 kidney transplant recipients also observed 60 episodes of pneumonia in 54 patients $(8.8 \%)$, of which 23 had a nosocomial origin (38\%) and 37 were community-acquired infections $(62 \%)$. Bacterial infection is the most frequent etiology (44\%), followed by fungal in $4(7 \%)$ and viral in $2(3.5 \%)$. The most commonly isolated microorganism in nosocomial pneumonia is $P$. aeruginosa ( $26 \%$, among which $50 \%$ were multidrug resistant). In $34 \%$ episodes, no microorganism is isolated. The most common pathogen among community-acquired pneumonias is S. pneumoniae ( $11 \%$ ). In $54 \%$ of cases, there is no microbiologic confirmation of disease. The overall accuracy of bronchoalveolar lavage is $72 \%$. When 21 patients with pneumonia (35\%) were admitted to the ICU; of these, 14 had a nosocomial infection $(60 \%)$ and 9 $(15 \%)$ died due to the infection $(\mathrm{p}=0.001){ }^{9}$

Data on heart transplant recipients has also shown that pneumonia is the most common complication. A prospective review of 307 heart transplant recipients found 21.1 cases of pneumonia per 100 heart transplantations. $75 \%$ of the cases occurred in the first 3 months, 82 causal agents are identified, of which $60 \%$ were opportunistic, 
$25 \%$ are nosocomial, and $15 \%$ were community-acquired. The most frequent isolates were CMV,20 aspergillus species, ${ }^{13}$ and pneumocystis carinii. ${ }^{11}$ Hemoptysis occurred more frequently in aspergillus pneumonias than in other pneumonias ( $54 \%$ vs. $6 \%$, respectively; $\mathrm{p}<.05$ ); aspergillus pneumonia is the only type of pneumonia during which cavitated nodules were noted on thoracic radiographs. The overall mortality rate was found to be $30.8 \%{ }^{10}$ Lenner et al reported 47 of 159 heart transplant recipients $(29.9 \%)$ had 81 pulmonary complications. 1including Pneumonia $(n=27)$, and bronchitis $(n=15){ }^{11}$ A retrospective review of 34 heart transplant recipients (31.3\%) who developed pulmonary complications, within first 6 months post-transplant showed Hospital-acquired bacterial pneumonia in 5 patients, fungal pneumonia in 3 patients, a post-transplant lymphoproliferative disease in 1 patient, and community-acquired pneumonia in 1 patient. Pneumonia-related mortality rate was $14.7 \%$ due to early-onset nosocomial pneumonias where bacterial and opportunistic microorganisms organisms were more commonly seen. ${ }^{12}$

SOT recipients are at risk of developing bacterial infections like nocardia. ${ }^{13}$ The risk of developing nocardiosis after SOT varies with the type of organ transplanted, e.g. lung transplant. In a review of 5126 organ transplant recipients has demonstrated that highest nocardial infection rate was seen among lung transplant recipients $(3.5 \%){ }^{14}$

Due to frequent exposure to antibiotics and repeated hospitalizations; SOT patients are at risk of developing intra-abdominal infections (IAI). IAI is commonly seen as a complication in post-liver, pancreas, multi-visceral transplants. Superinfection with MDR pathogens occurs frequently causing tertiary peritonitis. ${ }^{15}$ Clostridium difficile-associated disease (CDAD) is the most common cause of nosocomial diarrhea. One cohort study involving 4472 SOT patients observed that 42 episodes of CDAD were diagnosed in 36 patients $(0.94 \%)$. Median onset of infection was 31.5 days (range 6-741). It occurred during the first month after transplantation in half the cases and overall the prognosis was good. ${ }^{16}$

SOT recipients are at risk to develop viral infections leading to various nonspecific viral syndromes. Common viruses seen are CMV, EBV, and other viruses like herpesvirus, ${ }^{8}$ Zika virus, RNA respiratory viruses, adenovirus, norovirus, and polyomaviruses. ${ }^{17}$ Among viruses CMV virus disease which occurs during the first 3 months. With the introduction of CMV prophylaxis, this onset has been delayed. The seroprevalence rate of CMV ranges from $30-97 \%$. $^{18}$

The incidence of PCP in SOT recipients is variable. In a retrospective study of 1192 renal transplant patients, it was reported to be 0.6 to $9 \%$. They obsereved that the incidence of PCP with a moderate Cyclosporine based immunosuppressive regimen is low and seems to occur only in cases of additional immunosuppressive cofactors. ${ }^{19}$ In another retrospevtive study of 601 renal transplant recipients, PCP incidence was $2.2 \% .{ }^{20}$ In liver transplant recipients (154 adult patients) PCP occurred in 5.2\% and the authors observed that patients who developed PCP had more episodes of rejection $(p<0.05)$, received more OKT3 $(p<0.05)$, a prednisone $(p<0.05)$ than controls. ${ }^{21}$ Another retrospective study of 43 adult OLT recipients showed that the incidence of PCP was $0.9 \%$. Most of the patients developed PCP at around 1 year of post-OLT, and the risk of PCP was closely related to strong immunosuppressive regimen. Thus they advised that routine PCP prophylaxis for 12 months be continued for 12 months, among patients receiving antirejection treatment. ${ }^{22}$

Invasive fungal infection (IFIs) frequently complicates post SOT course. Cryptococcosis is a significant opportunistic infection in SOT recipients following aspergillosis and candidiasis. CSF analysis is highly recommended to diagnose underlying CNS disease in suspected cases. ${ }^{23}$ In Lung and heart transplant, $-2 \%$ incidence IFI of lung was noted and even dissemination can occur. Cryptococcus can colonize the airways of lung transplant recipients and can cause endobronchial fungal infection. It can present with skin manifestations and Immune reconstitution syndrome as well. ${ }^{24,25}$ In heart transplant recipients incidence of cryptococcus is 3\%, it manifests as sepsis and is associated with high mortality. ${ }^{26,27}$ In renal transplant recipients incidence of cryptococcus is $2.8 \%$ manifests as cryptoccocal necrotizing soft tissue infection. ${ }^{28}$ In liver transplant recipients the incidence is $2.4 \%$ and liver failure is independently associated with Cryptoccocal meningitis mortality. ${ }^{29}$ However, with wider employment of antifungal prophylaxis and improvements in transplantation practices, there is a decline in the overall incidence of IFIs. ${ }^{30,31}$ SOT reciepnts have risk of developing aspergillous particulary in lung trsnplant. A retrospective study involving 362 lung transplant recipients found that $105 / 335$ (31\%) patients had evidence of aspergillus infection (colonisation or invasion), 83 (25\%) patients had colonisation and $22(6 \%)$ patients had radiographic or histological evidence of invasive disease. Most of the infections occurred within the first 3 months after transplantation. Invasive aspergillosis (IA) was associated with $58 \%$ mortality after 2 years, while colonisation was associated with increased mortality after 5 years compared non-colonised patients $(\mathrm{p}<0.05) .{ }^{32}$ Hambrecht et alcompared voriconazole with amphotericin $b$ in their large randomized trial for the treatment of invasive aspergillosis (IA) in immunocompromised patients. ${ }^{33}$ 
After this trial voriconazole had been considered the preferred agent for IA. In their study they found that at week 12 , there were more successful outcomes $52.8 \%$ patients in the voriconazole group (complete response $20.8 \%$ and partial response in $31.9 \%$ ) compared to $31.6 \%$ in the amphotericin B group (complete response 16.5\% partial response in $15 \%$ ). The survival rate was better at 12 weeks in voriconazole compared to amphotericin B group. (71\% vs. 58\%) (HR- 0.59; 95\% CI- 0.40 to 0.88). After this study several studies were conducted for use of voriconazole for the treatment of IA, especially in patients of solid organ transplant recipient. J. Fortun et al in their case series reported of $100 \%$ complete response in four patients (two liver transplant, one lung transplant and one kidney transplant) of IA after treatment with voriconazole. ${ }^{34}$ Denning et al in their study showed good response in IA treated with voriconazole; 56 out of 60 patients in voriconazole group were treated successfully. ${ }^{35}$ Veroux et al reported complete response in four kidney transplant patients with IA treated with voriconazole. ${ }^{36}$ In another report that included 11 SOT recipients with central nervous system aspergillosis treated with voriconazole, the favorable response rate was 36\% and survival was $31 \% .{ }^{37}$ Voriconazole was successfully used in heart transplant recipients as first-line and salvage therapy for IA. ${ }^{38,39}$ Plasma drug level monitoring is important when voriconazole is used as the plasma levels achieved are variable and very often do not reach therapeutic levels in the plasma, requiring dose adjustments. ${ }^{40}$ The fact that clinical efficacy is dependent on the achievement of therapeutic drug levels has been well established. ${ }^{41}$

\section{CMV management}

- We recommend IV ganciclovir $5 \mathrm{mg} / \mathrm{kg}$ twice a day as the initial treatment for (I, A):

a. Severe or life-threatening CMV disease

b. Patients with high and increasing viral load

c. Patients with questionable gastrointestinal absorption

- Oral valganciclovir $900 \mathrm{mg}$ once a day is an effective initial therapy for mild to moderate CMV disease (I, A), or as a step down to iv ganciclovir after clinical improvement (II, B)

- We recommend against the use of acyclovir and oral ganciclovir for treating CMV disease (UPP, A).

- IV gamma globulin or preferably CMV-specific gamma globulin if available in the dose of $1 \mathrm{gm} / \mathrm{kg}$ over two days may be considered for patients with life-threatening disease, CMV pneumonitis (II, B).

- We recommend a duration of treatment for a minimum of two weeks. It should be continued until viral eradication is achieved either by weekly monitoring for viral load by real-time quantitative PCR (I, A).
- Therapy should be extended beyond two weeks if the clinical resolution is not seen or virus load continues to be high (I, A).

- After completion of full-dose antiviral treatment, a 1 to 3 months course of secondary prophylaxis may be considered depending on the clinical situation (II, B).

- Cautious reduction in immunosuppression should be considered in SOT patients presenting with CMV disease, especially if the disease is moderate to severe (II, B).

\section{Evidence Summary}

Drugs used for the treatment of CMV disease are IV Ganciclovir and oral valganciclovir. Oral ganciclovir should not be used due to poor bioavailability. Ganciclovir through IV route has been demonstrated as the treatment of choice in many trials. ${ }^{42-44}$ Asberg et al in a randomized controlled trial compared the outcome of CMV disease after treatment with IV Ganciclovir and oral valganciclovir. Three hundred twenty-one SOT recipients were enrolled and randomized to receive either twice daily intravenous ganciclovir or oral valganciclovir for 21 days followed by once daily valganciclovir until day 49 in all the patients. All patients were followed up for 1 year. The success rate was the same in both the groups with a similar rate of clinical and viral eradication. The clinical recurrence rate was also not statistically different in both the groups. ${ }^{43}$ In a retrospective study, the response to therapy was assessed using RT-PCR (2262 samples) and antigenemia using pp65 assay (1285 specimens). Both methods had $>90 \%$ specificity, but RT-PCR had better sensitivity. The authors concluded that RT-PCR was a more reliable tool to monitor the response to therapy. ${ }^{45}$ Failure to eradicate DNA-emia was the only independent predictor of recurrence in both the groups. The efficacy for the eradication of viremia was similar in both the groups, still many patients were viraemic even after treatment for 21 days, hence, duration of treatment should be individualized and based on clinical resolution and virologic clearance. ${ }^{46-48}$ There is a direct association between viral suppression below the lower limit of quantified test and disease resolution. Rapid resolution of CMV disease is seen with lower pre-treatment viral load (lower than $18,200 \mathrm{IU} / \mathrm{mL}){ }^{49}$

\section{PCP Management}

- We recommend trimethoprim-sulfamethoxazole (TMP-SMX) as the first-line agent and drug of choice with the Trimethoprim component being $20 \mathrm{mg} / \mathrm{kg}$ / day in 3 to 4 divided doses (I, A).

- In severe infections, if available, intravenous pentamidine probably remains the second-line agent after TMP-SMX (II, A). 
- In patients with hypoxemia $\left(\mathrm{PaO}_{2}<70 \mathrm{mmHg}\right.$ on room air), adjunctive corticosteroids should be administered with antimicrobial therapy, ideally within 72 hours of initiating antimicrobial therapy for maximum benefit (II, A). The dose of steroids should be $1 \mathrm{mg} / \mathrm{kg} /$ day prednisone (or equivalent) given in two divided doses daily for 5 to 7 days (II, A). Steroids should be tapered over a period of 7 to 14 days (II, B).

- Duration of antimicrobial therapy should be for at least 14 days (I, B).

\section{Evidence Summary}

TMP-SMX acts by interfering with folate metabolism and remains the drug of choice for treatment of PCP in SOT patients, HIV patients, and non-HIV patients. TMP-SMX has high efficacy and availability in both oral and IV preparation with good oral bioavailability too. ${ }^{50}$ Intravenous pentamidine has been found to be equally effective in HIV-infected patients and remains the second line of choice for treatment of PCP in SOT patients. ${ }^{51-55}$ However, the use of pentamidine has been largely limited in view of its numerous toxicities in $71 \%$ patients leading to withdrawal in around $18 \%$ patients. ${ }^{52}$ The optimal duration of therapy is usually 14 days which can be extended to 21 days in severe cases with slow clinical improvement. ${ }^{56}$ Adjunctive glucocorticoids are recommended for HIVpositive patients with moderate to severe $\mathrm{PCP}$, defined as $\mathrm{PaO}_{2}<70 \mathrm{mmHg}$ while breathing ambient room air. ${ }^{57}$ The benefit in survival from corticosteroids begins during the first 72 hours of treatment. ${ }^{58}$ Bolée et al's study found a trend for longer survival in patients who received adjunctive steroids $(\mathrm{p}=0.07) .{ }^{59}$ In Pareja et al's study, there was no difference in the mortality rates of patients treated with adjunctive high-dose steroids, but they did spend less time on mechanical ventilation compared to patients not managed with steroids. ${ }^{60}$

\section{Tuberculosis in SOT Recipient}

\section{Evidence Statements}

- The diagnosis of active TB in transplant recipients requires a high index of suspicion. Although the diagnostic modalities and treatment of TB in SOT patients remains the same as that in immunocompetent hosts, these individuals often require an invasive procedure, such as bronchoscopy with bronchoalveolar lavage or lung biopsy (I, A).

- Rifamycins, particularly rifampin, reduce serum concentrations of tacrolimus, cyclosporine, rapamycin (sirolimus), and everolimus via induction of the cytochrome p450 isoenzyme CYP3A4, necessary dose adjustments, and therapeutic drug monitoring are warranted to avoid development of rejection (II, A). When rifampin is not used, a longer than usual duration of treatment is required (II, B).

\section{Evidence Summary}

Given that tuberculosis is an immunological disease and with the high prevalence of TB in India, the incidence of active tuberculosis infection is higher among SOT recipients as compared to the general population. ${ }^{61,62}$ The diagnosis of $\mathrm{TB}$ in SOT recipients presents challenges that may lead to treatment delay. These include atypical clinical presentations, increased likelihood of negative tuberculin skin tests and/or IGRA, and negative sputum smear results despite active disease makes TB diagnosis in SOT recipients a challenge. ${ }^{61,63-65}$ One-third to one-half of cases of tuberculosis after transplant are disseminated or extrapulmonary. Lung transplant recipients are most likely to develop pulmonary manifestations of TB. Similarly, drug-drug interactions between immunosuppressive and AKT, allograft-related drug toxicities, and inadequate immune responses to TB makes treatment of $\mathrm{TB}$ in transplant recipients also very challenging. ${ }^{63-65}$

\section{Infective diarrhea in SOT patients}

\section{Evidence Statements}

- We recommend empiric management of GI infections with ceftriaxone iv + ganciclovir $5 \mathrm{~g} / \mathrm{kg}$ BD IV and vancomycin $125 \mathrm{mg}$ PO QID (if the patient is already on antibiotics to cover $\mathrm{CDI}$ ) till definitive diagnosis is made (I, A).

- If the patient is in septic shock, based on local resistance pattern, and previous drug history of patient consider carbapenems (UPP, A).

- We recommend cessation of the inciting antimicrobial agent whenever possible (II, A).

- We recommend NAAT for the diagnosis of CDI (I, A).

- For mild-to-moderate CDI we recommend oral metronidazole (I, A). Dose of metronidazole $500 \mathrm{mg}$ TID for adults.

- We recommend oral vancomycin for the treatment of severe CDI (IA). The accepted dose of vancomycin is $125 \mathrm{mg}$ qid for adults and 40 to $50 \mathrm{mg} / \mathrm{kg} /$ day divided QID for pediatric patients (not to exceed adult dosing).

- In severe CDI with complications, a dose of oral vancomycin may be increased up to 500 mg orally QID.

- Vancomycin may be administered by retention enema (IIB), and intravenous metronidazole may be added (IIC).

- Feacal transplant may be considered in recurrent or relapsing CDI (II, B). 
- We suggest consideration for surgical intervention in cases of complicated CDI. (II, B).

- In cases of multiple recurrences of CDI, we recommend prolonged courses of oral vancomycin, either in a tapering or pulse dose schedule (II, A). Fidaxomicin can be used if available (II, B)

Table 3: Common causes of diarrhea in SOT patients

\begin{tabular}{|c|c|}
\hline \multicolumn{2}{|l|}{ Common } \\
\hline & - $\quad$ CMV infection \\
\hline & - Clostridium difficile infections (CDI) \\
\hline & $\begin{array}{l}\text { - Small bowel bacterial growth (SBBO): } \\
\text { Escherichia coli, Campylobacter, Shigella, } \\
\text { Salmonella }\end{array}$ \\
\hline & - $\quad$ MMF drug therapy \\
\hline \multicolumn{2}{|l|}{ Unusual } \\
\hline & $\begin{array}{l}\text { Infections other than CMV and bacterial: } \\
\text { Viruses (adenovirus, astrovirus, human herpes } \\
\text { virus } 6 / \text { hhv-6, norovirus, dengue fever), } \\
\text { fungi (candida), and parasites (blastocystis, } \\
\text { hymenolepis nana, trichuristrichiura, isospora } \\
\text { belli, and Entamoeba }\end{array}$ \\
\hline & - $\quad$ Non-infectious colitis (IBD) \\
\hline & - Drugs other than MMF \\
\hline \multicolumn{2}{|l|}{ Rare } \\
\hline & - $\quad$ GVHD \\
\hline & - $\quad$ PTLD \\
\hline & - $\quad$ Microscopic colitis \\
\hline & - Colon cancer \\
\hline
\end{tabular}

\section{Evidence Summary}

Due to frequent exposure to antibiotics and repeated hospitalizations SOT patients are a risk of developing intra-abdominal infections (IAI). IAI is commonly seen as a complication in post-liver, pancreas, multivisceral transplantation and superinfection with MDR pathogens occur frequently causing tertiary peritonitis ${ }^{66}$ Common causes of diarrhea are as mentioned in Table 3. The treatment of choice for CDI had been oral vancomycin. Vancomycin has been shown to have much better efficacy compared to metronidazole in many studies. Zar et al in their randomized controlled trial in 150 patients found that both metronidazole and vancomycin were equally effective in treating mild CDI, but Vancomycin was much more effective in treating severe CDI ${ }^{67}$ The clinical cure rate in mild CDI was $90 \%$ and $98 \%$ with metronidazole and vancomycin respectively $(\mathrm{p}=0.36)$. In severe CDI the cure rates were $76 \%$ and $97 \%$ respectively $(p=0.02)$. Recurrence rates were also comparable in both the groups. Fekety et al in their randomized controlled trial compared two doses regimen of vancomycin in 46 patients viz. 125 $\mathrm{mg}$ four times a day vs. $500 \mathrm{mg}$ four times a day. ${ }^{68}$ They found no difference in measurable responses to the two regimens. Since $125 \mathrm{mg}$ four times a day is more costeffective $125 \mathrm{mg}$ dose is recommended. Even $125 \mathrm{mg}$-dose produces stool concentration of vancomycin of around 100 times more than the minimal inhibitory concentration (MIC) for C. difficile. ${ }^{69}$ The usual dose of oral vancomycin for children is $40 \mathrm{mg} / \mathrm{kg}$ daily given in three or four divided doses. Fecal microbiota transplantation (FMT) in the management of refractory CDI has gained popularity recently, although in SOT recipients it has theoretical safety concerns. A series of cases ( 75 adults and 5 pediatric patients) treated with FMT for recurrent, refractory, and severe and/or overlap of recurrent/refractory and severe CDI had $78 \%$ cure rate after first FMT. ${ }^{70}$ There were no related infectious complications or adverse events in these high-risk patients.

\section{CNS Infections}

\section{Evidence Statements}

- We recommend initial workup for suspected CNS infections should include (I, A)

a. MRI over CT scan

b. CSF analysis including India ink preparation

c. Rapid multiplex PCR on CSF

d. Serum cryptococcal antigen

- We recommend empiric treatment to be started with Ceftriaxone + Vancomycin + Acyclovir (I, A)

- We recommend Liposomal Amphotericin B as the initial treatment for Cryptococcus. (I, A)

\section{Evidence Summary}

SOT patients with altered sensorium should be evaluated with detailed workup. Multifactorial etiologies coexist which are often obscured in these group of patients. ${ }^{71}$ Common pathogens causing CNS infections in SOT recipients are mentioned in Table 4. Although each imaging modality has unique insight to diagnose pathophysiology, but magnetic resonance imaging (MRI) is the preferred modality. It can diagnose infectious as well as non-infectious etiologies like drug toxicities, metabolic disorders as well as the progression of the disease and response to the therapy. ${ }^{72,73}$ Empiric broad-spectrum antimicrobial therapy including viral and fungal infections are preferred. It is preferred to use empirical bactericidal or fungicidal agents having CNS penetration until a diagnosis is achieved. ${ }^{71}$ There has been always a risk of donor-derived infections in SOT recipients thus donors should be screened with standard screening tests. ${ }^{74,75}$ 
Table 4: Common pathogens causing CNS Infections in SOT recipients

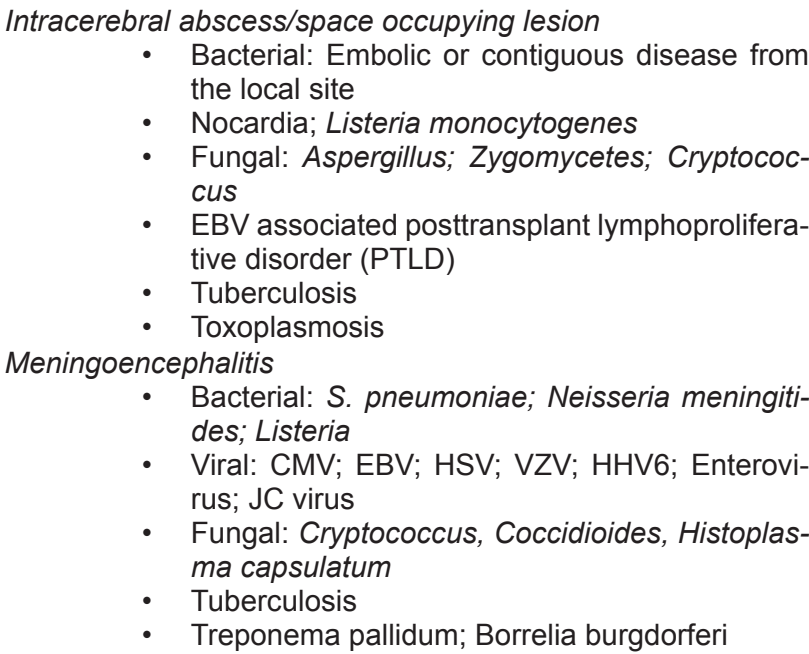

\section{Nocardia: Post transplantation}

- We recommend the following regimens for treatment of post-transplant nocardia infections

1. Pulmonary: TMP-SMX (I, A)

2. Disseminated or CNS, Critically ill: Imipenem plus TMP-SMX or Amikacin (I, A)

3. Alternative: Meropenem, Linezolid (I, A)

\section{Evidence Summary}

SOT recipients are at risk of developing nocardia infection which is an opportunistic event. ${ }^{76}$ The risk of developing nocardiosis after SOT varies with the type of organ transplanted, e.g., the highest incidence in recipients of a lung transplant. A review of 5126 organ transplant recipients has demonstrated that highest nocardial infection rate among lung transplant recipients (3.5\%). ${ }^{77} \mathrm{TMP}-\mathrm{SMX}$ is the treatment of choice for nocardial infections as it has demonstrated clinical efficacy and achieves high tissue concentrations in lung, brain, skin, and bone. Combination therapy is recommended in critically ill patients with pulmonary nocardia, cerebral nocardia, and disseminated nocardia. ${ }^{78}$ Linezolid has shown good activity against all species of nocardia. ${ }^{79}$

\section{REFERENCES}

1. Fishman JA. Infection in Renal Transplant Recipients. Semin Nephrol . 2007;27:445-61.

2. Al-Hasan MN, Razonable RR, Eckel-Passow JE, Baddour LM. Incidence rate and outcome of gram-negative bloodstream infection in solid organ transplant recipients. Am J Transplant. 2009;9:835-43.

3. Ram R, Dakshin Murty K, PrasadN. Time table of infections after renal transplantation - SouthIndian experience. Indian J Nephrol Indian J Nephrol. 2005;15:14-21.

4. Sriperumbuduri S, Kalidindi K, Guditi S, Taduri G. Declining trend of infections in renal transplant recipients in a tertiary care hospital from India. Indian J Transplant 2017;11:143-148.

5. Kumar A, Agarwal C, Hooda AK, Ojha A, Dhillon M, Hari Kumar K.: J Family Med Prim Care 2016;5:611-4

6. Wang ZX, Song SH, Teng F, Wang GH, Guo WY, Shi XM, Ma J, et al. Clin Transplant. 2010;24:752-7.

7. Giannella M, Muñoz P, Alarcón JM, Mularoni A, Grossi P, Bouza E; PISOT study group. Pneumonia in solid organ transplant recipients: a prospective multicenter study. Transpl Infect Dis. 2014;16:232-41

8. Dizdar OS, Ersoy A, Akalin H. Pneumonia after kidney transplant: Incidence, risk factors, and mortality. Exp Clin Transplant. 2014;12:205-11.

9. Hoyo I, Linares L, Cervera C, Almela M, Marcos MA, Sanclemente G, Cofán F, et al. Epidemiology of pneumonia in kidney transplantation. Transplant Proc. 2010;42:2938-40.

10. Cisneros JM, Muñoz P, Torre-Cisneros J, Gurgui M, RodriguezHernandez MJ, Aguado JM, et al. Pneumonia after heart transplantation: a multi-institutional study. Spanish Transplantation Infection Study Group. Clin Infect Dis. 1998;27:32431.

11. Lenner R, Padilla ML, Teirstein AS, Gass A, Schilero GJ. Chest. Pulmonary complications in cardiac transplant recipients. 2001;120:508-13.

12. Atasever A, Bacakoglu F, Uysal FE, Nalbantgil S, Yagdi T, Guzelant A, Sayiner A. Pulmonary complications in heart transplant recipientsTransplant Proc. 2006;38:1530-4.

13. Lebeaux D, Freund R, Van Delden C, Guillot H, Marbus $\mathrm{SD}$, Matignon M, Van Wijngaerden E, et al. Outcome and Treatment of Nocardiosis after Solid Organ Transplantation: New Insights from a European Study. Clin Infect Dis. 2017;64:1396-405

14. Peleg AY, Husain S, Qureshi ZA, Silveira FP, Sarumi M, Shutt KA, Kwak EJ, et al. Risk factors, clinical characteristics, and outcome of Nocardia infection in organ transplant recipients: A matched case-control study. Clin Infect Dis 2007;44:13071314

15. Cervera C, van Delden C, Gavaldà J, Welte T, Akova M, Carratalà J. Multidrug-resistant bacteria in solid organ transplant recipients. Clin Microbiol Infect. 2014;20 (s7):49-73.

16. Len O, Rodríguez-Pardo D, Gavaldã J, Aguado JM, Blanes M, Borrell N, Bou G, et al. Outcome of Clostridium difficileassociated disease in solid organ transplant recipients: A prospective and multicentre cohort study. Transpl Int. 2012;25:1275-81.

17. Haidar G, Singh N. Viral infections in solid organ transplant recipients. Current Opinion in Infectious Diseases 2017;30:579-588.

18. Razonable RR, Humar A. Cytomegalovirus in Solid Organ Transplantation. American Journal of Transplantation. 2013;13(s4):93-106.

19. Lufft V, Kliem V, Behrend M, Pichlmayr R, Koch KM, Brunkhorst R. Incidence of Pneumocystis carinii pneumonia after renal transplantation. Impact of immunosuppression. Transplantation. 1996;62:421-3.

20. Borstnar S, Lindic J, Tomazic J, Kandus A, Pikelj A, Prah J, Skvarc M, et al. Pneumocystis jirovecii pneumonia in renal transplant recipients: a national center experience Transplant Proc. 2013;45:1614-7.

21. Hayes MJ, Torzillo PJ, Sheil AG, McCaughan GW. Pneumocystis carinii pneumonia after liver transplantation in adults Clin Transplant. 1994;8:499-503 
22. Choi YI, Hwang S, Park GC, Namgoong JM, Jung DH, Song GW, Ha TY, et al. Clinical outcomes of Pneumocystis carinii pneumonia in adult liver transplant recipients Transplant Proc. 2013;45:3057-60

23. Henao-Martínez, A. F., Beckham, J. D. Cryptococcosis in solid organ transplant recipients. Current Opinion in Infectious Diseases 2015;28:300-307.

24. Rakvit A, Meyerrose G, Vidal AM, Kimbrough RC, Sarria JC. Cellulitis caused by Cryptococcus neoformans in a lung transplant recipient. J Heart Lung Transplant 2005;24:642

25. Singh N, Lortholary O, Alexander BD, Gupta KL, John GT, Pursell K, Munoz P, et al. An immune reconstitution syndrome-like illness associated with Cryptococcus neoformans infection in organ transplant recipients. Clin Infect Dis 2005;40:1756-1761.

25. Legris T, Massad M, Purgus R, Vacher-Coponat H, Ranque S, Girard N, Berland Y, Moal V. Immune reconstitution inflammatory syndrome mimicking relapsing Cryptococcal meningitis in a renal transplant recipient. Transplant Infect Dis 2011;13:303-308.

26. Hsu RB, Chang CI, Fang CT, Chang SC, Wang SS, Chu SH. Bloodstream infection in heart transplant recipients: 12-year experience at a university hospital in Taiwan. Eur J Cardiothorac Surg 2011;40:1362-1367.

27. Chou NK, Chi NH, Wu IW, Huang SC, Chen YS, Yu HY, Tsao CI, et al. Fungal infection in heart transplant recipients with severe sepsis: single-center experience. Transplant Proc 2010;42:952-954.

28. Baer S, Baddley JW, Gnann JW, Pappas PG. Cryptococcal disease presenting as necrotizing cellulitis in transplant recipients. Transpl Infect Dis 2009;11:353-358.

29. Wu G, Vilchez RA, Eidelman B, Fung J, Kormos R, Kusne S. Cryptococcal meningitis: an analysis among 5521 consecutive organ transplant recipients. Transpl Infect Dis 2002;4:183-188.

30. Singh N, Paterson DL. Aspergillus infections in transplant recipients. Clin Microbiol Rev 2005;18:44.

31. Fortun J, Martin-Davila P, Moreno S, Barcena R, de Vicente E, Honrubia A, Garcia M, et al. Prevention of invasive fungal infections in liver transplant recipients: the role of prophylaxis with lipid formulations of amphotericin B in high-risk patients. J Antimicrob Chemotherap 2003;52:813-819.

32. Iversen $M$, Burton CM, Vand S, Skovfoged L, Carlsen J, Milman N, Andersen CB, et al.: Eur J Clin Microbiol Infect Dis. 2007;26:879-86.

33. Herbrecht R, Denning DW, Patterson TF, Bennett JE, Greene RE, Oestmann JW, Kern WVet al. Voriconazole versus amphotericin B for primary therapy of invasive aspergillosis. N Engl J Med 2002;347:408-415.

34. Fortun J, Martín-Dávila P, Sánchez MA, Pintado V, Alvarez ME, Sánchez-Sousa A, Moreno S.. Voriconazole in the treatment of invasive mold infections in transplant recipients. Eur J Clin Microbiol Infect Dis. 2003;22:408-413.

35. Denning DW, Ribaud P, Milpied N, Caillot D, Herbrecht R, Thiel E, Haas A, et al. Efficacy and safety of voriconazole in the treatment of acute invasive aspergillosis. Clin Infect Dis 2002;34:563-571.

36. Veroux M, Corona D, Gagliano M, Sorbello M, Macarone M, Cutuli M, Giuffrida G, et al. Voriconazole in the treatment of invasive aspergillosis in kidney transplant recipients. Transplant Proc 2007;39:1838-1840.

37. Schwartz S, Ruhnke M, Ribaud P, Corey L, Driscoll T, Cornely $\mathrm{OA}$, Schuler $\mathrm{U}$, et al. Improved outcome in central nervous system aspergillosis, using voriconazole treatment. Blood 2005;106:2641-2645.

38. Wéclawiak H, Garrouste C, Kamar N, Linas MD, Tall P, Dambrin C, Durand D, et al. Aspergillus fumigatus related spondylodiscitis in a heart transplant patient successfully treated with voriconazole. Transplant Proc 2007;39:26272628.

39. Wieland T, Liebold A, Jjagiello M, Retzl G, Birnbaum De. Superiority of voriconazole over amphotericin $\mathrm{b}$ in the treatment of invasive aspergillosis after heart transplantation. J heart lung transplant 2005;24:102-104.

40. Yi WM, Schoeppler KE, Jaeger J, Mueller SW, MacLaren R, Fish $\mathrm{DN}$, Kiser TH. Voriconazole and posaconazole therapeutic drug monitoring: A retrospective study. Annals of Clinical Microbiology and Antimicrobials 2017;16:60

41. Troke PF, Hockey HP, Hope WW. Observational study of the clinical efficacy of voriconazole and its relationship to plasma concentrations in patients. Antimicrob Agents Chemother. 2011;55:4782-8

42. Conti DJ, Freed BM, Singh TP, Gallichio M, Gruber SA, Lempert N. et al. Preemptive Ganciclovir Therapy in Cytomegalovirus-Seropositive Renal Transplants Recipients. Arch Surg. 1995;130:1217-1222

43. Asberg A1, Humar A, Rollag H, Jardine AG, Mouas $H$, Pescovitz MD, Sgarabotto D, et al. Oral valganciclovir is noninferior to intravenous ganciclovir for the treatment of cytomegalovirus disease in solid organ transplant recipients. Am J Transplant 2007;7:2106-2113.

44. Hibberd PL, Tolkoff-Rubin NE, Conti D, Stuart F, Thistlethwaite JR, Neylan JF, Snydman DR, et al. Preemptive ganciclovir therapy to prevent cytomegalovirus disease in cytomegalovirus antibody-positive renal transplant recipients. A randomized controlled trial. Ann Intern Med 1995;123:1826.

45. Marchetti S, Santangelo R, Manzara S, D'Onghia S, Fadda G, Cattani P. Comparison of real-time PCR and pp65 antigen assays for monitoring the development of cytomegalovirus disease recipients of solid organ and bone marrow transplants. New Microbiol 2011;34:157-164.

46. Humar A, Kumar D, Boivin G, Caliendo AM. Cytomegalovirus $(\mathrm{CMV})$ virus load kinetics to predict recurrent disease in solid-organ transplant patients with $\mathrm{cmv}$ disease. J infect dis 2002;186:829-833.

47. Sia IG, Wilson JA, Groettum CM, Espy MJ, Smith TF, Paya CV. Cytomegalovirus (CMV) DNA Load Predicts Relapsing CMV Infection after Solid Organ Transplantation. J Infect Dis. 2000;181:717-20.

48. Asberg A, Humar A, Jardine AG, Rollag H, Pescovitz MD, Mouas H, Bignamini A, et al. Long-term outcomes of $\mathrm{cmv}$ disease treatment with valganciclovir versus iv ganciclovir in solid organ transplant recipients. Am J Transplant 2009;9:1205-1213.

49. Razonable RR, Åsberg A, Rollag H, Duncan J, Boisvert D, Yao JD, Caliendo AM, et al. Virologic suppression measured by a cytomegalovirus (CMV) DNA test calibrated to the world health organization international standard is predictive of CMV disease resolution in transplant recipients. Clin Infect Dis 2013;56:1546-1553.

50. Martin SI, Fishman JA; AST Infectious Diseases Community of Practice. Pneumocystis pneumonia in solid organ transplantation. Am. J. Transplant. 2013;13:272-279. 
51. Klein NC, Duncanson FP, Lenox TH, Forszpaniak C, Sherer $\mathrm{CB}$, Quentzel H, Nunez M et al. Trimethoprim-sulfamethoxazole versus pentamidine for Pneumocystis carinii pneumonia in AIDS patients: Results of a large prospective randomized treatment trial. AIDS 1992;6:301-305.

52. O'Brien JG, Dong BJ, Coleman RL, Gee L, Balano KB. A 5 -year retrospective review of adverse drug reactions and their risk factors in human immunodeficiency virus-infected patients who were receiving intravenous pentamidine therapy for Pneumocystis carinii pneumonia. Clin. Infect. Dis. 1997;24:854-859.

53. Benfield T, Atzori C, Miller RF, Helweg-Larsen J. Second-line salvage treatment of AIDS-associated Pneumocystis jirovecii pneumonia: A case series and systematic review. J Acquir Immune Defic Syndr. 2008;48:63-6

54. Kim T, Hong HL, Lee YM, Sung H, Kim SH, Choi SH, Kim YS, et al. Is Caspofungin really an effective treatment for Pneumocystis jirovecii pneumonia in immunocompromised patients without human immunodeficiency virus infection? Experiences at a single center and a literature review. Scand. J. Infect. Dis. 2013;45:484-488.

55. Fishman JA. Treatment of infection due to Pneumocystis carinii. Antimicrob Agents Chemother. 1998;42:1309-1314.

56. Roux A, Gonzalez F, Roux M, Mehrad M, Menotti J, Zahar JR, Tadros VX, et al. Update on pulmonary Pneumocystis jirovecii infection in non-HIV patients. Med Mal Infect. 2014;44:185-198

57. Ewald H, Raatz H, Boscacci R, Furrer H, Bucher HC, Briel M.. Adjunctive corticosteroids for Pneumocystis jirovecii pneumonia in patients with HIV-infection. Cochrane Database Syst Rev. 2015;4:CD006150.

58. Catherinot E, Lanternier F, Bougnoux ME, Lecuit M, Couderc LJ, Lortholary O. Pneumocystis jirovecii Pneumonia. Infect Dis Clin North Am. 2010;24:107-38.

59. Bollée G, Sarfati C, Thiéry G, Bergeron A, de Miranda S, Menotti J, de Castro N, et al. Clinical picture of Pneumocystis jirovecii pneumonia in cancer patients. Chest 2007;132:13051310.

60. Pareja JG, Garland R, Koziel H. Use of adjunctive corticosteroids in severe adult non-HIV Pneumocystis carinii pneumonia. Chest 1998;113:1215-1224.

61. Subramanian AK, Morris MI, AST Infectious Diseases Community of Practice. Mycobacterium tuberculosis infections in solid organ transplantation. Am J Transplant 2013;13 Suppl 4:68.

62. Torre-Cisneros J, Doblas A, Aguado JM, San Juan R, Blanes M, Montejo M, Cervera C, et al; Spanish Network for Research in Infectious Diseases. Tuberculosis after solid-organ transplant: incidence, risk factors, and clinical characteristics in the RESITRA (Spanish Network of Infection in Transplantation) cohort, Clin Infect Dis. 2009;48:1657-65.

63. Muñoz P, Rodríguez C, Bouza E. Mycobacterium tuberculosis infection in recipients of solid organ transplants. Clin Infect Dis 2005;40:581-7.
64. Subramanian AK. Tuberculosis in solid organ transplant candidates and recipients: current and future challenges. Curr Opin Infect Dis 2014;27:316-21

65. Horne DJ, Narita M, Spitters CL, Parimi S, Dodson S, Limaye AP.. Challenging issues in tuberculosis in solid organ transplantation. Clin Infect Dis 2013;57:1473-82.

66. Cervera C, van Delden C, Gavaldà J, Welte T, Akova M, Carratalà J; ESCMID Study Group for Infections in Compromised Hosts. Multidrug-resistant bacteria in solid organ transplant recipients. Clin Microbiol Infect. 2014;20(s7):49-73.

67. Zar FA, Bakkanagari SR, Moorthi KM, Davis MB. A comparison of vancomycin and metronidazole for the treatment of clostridiumdifficile-associated diarrhea, stratified by disease severity. Clin Infect Dis. 2007;45:302-7.

68. Fekety R, Silva J, Kauffman C, Buggy B, Deery HG. Treatment of antibiotic-associated clostridium difficile colitis with oral vancomycin: comparison of two dosage regimens. Am J Med. 1989; 86:15-19.

69. Hecht DW, Galang MA, Sambol SP, Osmolski JR, Johnson $\mathrm{S}$, Gerding DN. In vitro activities of 15 antimicrobial agents against 110 toxigenic clostridium difficile clinical isolates collected from 1983 to 2004. Antimicrob Agents Chemother. 2007;51:2716-9

70. Kelly CR, Ihunnah C, Fischer M. Fecal Microbiota Transplant for Treatment of Clostridium difficile Infection in Immunocompromised Patients. Am J Gastroenterol. 2017;109:1065-71.

71. Wright AJ, Fishman JA. Central nervous system syndromes in solid organ transplant recipients. Clin Infect Dis. 2014;59:100111.

72. Živkovi S. Neuroimaging and neurologic complications after organ transplantation. J Neuroimaging. 2007;17:110-23.

73. Fishman JA. Infection in Renal Transplant Recipients. Semin Nephrol 2007;27:445-61.

74. Grossi PA, Fishman JA. AST Infectious Disease Community of Practice. Donor-derived infections in solid organ transplant recipients. Am J Transplant 2009;9(suppl 4):S19-26.

75. Ison MG, Nalesnik MA. An update on donor-derived disease transmission in organ transplantation. Am J Transplant 2011;11:1123-30.

76. Lebeaux D, Freund R, Van Delden C, Guillot H, Marbus SD, Matignon M, et al. Outcome and Treatment of Nocardiosis after Solid Organ Transplantation: New Insights from a European Study. Clin Infect Dis. 2017;64:1396-405.

77. Peleg AY, Husain S, Qureshi ZA, Silveira FP, Sarumi M, Shutt KA, Kwak EJ, et al. Risk factors, clinical characteristics, and outcome of Nocardia infection in organ transplant recipients: A matched case-control study. Clin Infect Dis 2007;44:13071314.

78. Clark NM, Reid GE. Nocardia infections in solid organ transplantation. Am J Transplant. 2013;13(Supl 4):83-92.

79. Moylett EH1, Pacheco SE, Brown-Elliott BA, Perry TR, Buescher ES, Birmingham MC, Schentag JJ, et al. Clinical experience with linezolid for the treatment of Nocardia infection. Clin Infect Dis 2003;36:313-318. 


\section{PART 3. THE HUMAN IMMUNODEFICIENCY VI- RUS (HIV) POSITIVE PATIENT IN THE INTENSIVE CARE UNIT}

These guidelines are applicable to a patient who is known to be infected with the human immunodeficiency virus (HIV) or presents for the first time to ICU with AIDSdefining conditions.

With the advent of highly active anti retroviral therapy (HAART) era and the Test and Treat policy in HIV (where anyone testing positive receives HAART irrespective of CD4 cell counts). The incidence of ICU admissions for an HIV related illness is decreasing. Although HIV infected patients may still seek intensive care for reasons related directly to HIV infection, more and more seek care for other conditions that are unrelated to HIV such as trauma, infections, and other chronic diseases. Except for some special conditions such as opportunistic infections or HIV related treatment complications, HIV-infected patients are managed similarly to other patients without HIV infection. The treating physician should be aware of drug interactions, infectious and noninfectious conditions as a cause of the clinical presentation. ${ }^{1}$

\section{The HIV patient in ICU with Acute respiratory failure}

\section{Evidence statements}

- Appropriate samples should be collected for staining and cultures-including sputum/induced sputum and bronchoscopic lavage-if indicated. (UPP, A)

- Patients with severe pneumonia who require intensive care and without risk of Pseudomonas aeruginosa should be empirically treated with an IV $\beta$-lactam plus IV macrolide (II, A). Preferred $\beta$-lactams are ceftriaxone, cefotaxime, or amoxicillin-clavulanic acid. In patients who are allergic to penicillin, aztreonam plus azithromycin should be used (III, B).

- Those with CD4 counts $<200 / \mathrm{mm}^{3}$ and without signs of focal consolidation may be suspected to have PCP and should receive Trimethoprim-sulphamethoxazole (Co-trimoxazole) in therapeutic dose (TMP 15-20 mg/ $\mathrm{kg}$ / day plus SMX 75 to $100 \mathrm{mg} / \mathrm{kg} /$ day given $\mathrm{q} 6 \mathrm{~h}$ or q8h). (I, A)

- Patients with documented or suspected Pneumocystis Jerovecii pneumonia (PCP) pneumonia and moderateto-severe disease, defined by room air $\mathrm{PO}_{2}<70 \mathrm{~mm} \mathrm{Hg}$ or Alveolar-arterial $\mathrm{O}_{2}$ gradient $\geq 35 \mathrm{mmHg}$, should receive adjunctive corticosteroids as early as possible and certainly within 72 hours after starting specific PCP therapy (I, A)

- If patients with HIV / AIDS develop acute respiratory failure and they have any of the risk factors for Pseu- domonas infection we recommend dual antipseudomonal coverage such as anti-pseudomonal $\beta$-lactam plus aminoglycoside (examples of anti-pseudomonal $\beta$-lactams include ceftazidime, cefoperazone, cefoperazone-sulbactam, piperacillin-tazobactam, imipenemcilastatin, or meropenem (III, A). In patients who are allergic to penicillin, aztreonam can be used in place of the $\beta$-lactam. Combination therapy may be considered with the addition of aminoglycosides or antipseudomonal fluoroquinolones (e.g., levofloxacin, ciprofloxacin) (III, B).

- We recommend continuing Azithromycin along with anti-pseudomonal therapy for coverage of atypical pathogens (II, B).

- We recommend against using fluoroquinolones empirically to avoid development of drug-resistant TB. Patients should also undergo sputum testing for acid-fast bacilli simultaneously if fluoroquinolones are being used. Fluoroquinolones may be continued only if tuberculosis is not a diagnostic consideration at admission (I, A).

- In patients who have risk factors for methicillin-resistant Staphylococcus aureus (MRSA) infection-empiric treatment should include vancomycin or linezolid (III, B).

- We suggest the addition of clindamycin (to vancomycin, but not to linezolid) in cases of severe necrotizing pneumonia to minimize bacterial toxin production (III, B).

- When the etiology of pneumonia has been identified on the basis of reliable microbiological methods, antimicrobial therapy should be de-escalated (II, A).

- A switch to oral therapy should be considered in patients with community acquired pneumonia (CAP) on IV antibiotic therapy who have improved clinically, can swallow and tolerate oral medications, and have intact gastrointestinal function (II, A).

\section{Evidence Summary}

Respiratory failure is the most important cause of ICU admission among HIV patients. However, the specific microbiology data on etiology among HIV positive patients in the ICU is lacking from the Indian sub-continent. After going through the available literature, the most common pathogens seem to be viral infections, Pneumocystis Jirovecii, Streptococcal pneumoniae, H. Influenzae, M. tuberculosis, Staphylococcus aureus, Klebsiella pneumoniae, Pseudomonas aeruginosa, and Escherichia coli ${ }^{2}$ (Table 1). These patients are highly susceptible to infections with Mycobacterium tuberculosis (MTB). Hence MTB should be actively searched and ruled out in this population, 
Table 1: Etiology of acute respiratory failure in patients with HIV

\begin{tabular}{|c|c|c|c|}
\hline $\begin{array}{l}\text { Author/ } \\
\text { Country }\end{array}$ & Design & Study population & Microbiology \\
\hline $\begin{array}{l}\text { Chiang et al } \\
\text { Taiwan }^{3}\end{array}$ & $\begin{array}{l}\text { Retrospective } \\
\text { study }\end{array}$ & $\begin{array}{l}\text { HIV-infected adults admitted to } \\
\text { ICU from } 2001 \text { to } 2010\end{array}$ & P. jirovecii pneumonia, cytomegalovirus (CMV) pneumonitis \\
\hline $\begin{array}{l}\text { Barbier et al, } \\
\text { France }^{4}\end{array}$ & $\begin{array}{l}\text { Retrospective } \\
\text { study }\end{array}$ & $\begin{array}{l}\text { HIV-infected patients admitted } \\
\text { ICU for respiratory failure from } \\
1996 \text { to } 2006 .\end{array}$ & $\begin{array}{l}\text { Bacterial pneumonia, } \\
\text { Pneumocystis jirovecii pneumonia (PCP) } \\
\text { Other opportunistic infections }\end{array}$ \\
\hline $\begin{array}{l}\text { Alves et al } \\
\text { Barcelona }^{5}\end{array}$ & $\begin{array}{l}\text { Prospectively } \\
\text { study }\end{array}$ & $\begin{array}{l}\text { HIV patients in ICU } \\
\text { 1993-1998 }\end{array}$ & $\begin{array}{l}\text { Pneumocystis jirovecii pneumonia (PCP) } \\
\text { bacterial } \\
\text { Strep and Mtb }\end{array}$ \\
\hline $\begin{array}{l}\text { Kuan-Yeh Lee } \\
\text { Taiwan }^{6}\end{array}$ & $\begin{array}{l}\text { Prospectively } \\
\text { evaluated }\end{array}$ & $\begin{array}{l}\text { Hospitalized patients } \\
\text { July } 2009 \text { to March } 2012 \text {, }\end{array}$ & $\begin{array}{l}\text { Pneumocystis pneumonia-in those with CD } 4 \text { count }<200 \text { cells/ } \\
\mathrm{mm}^{3} \\
\text { In patients with a CD } 4 \text { count }>200 \text { cells } / \mathrm{mm}^{3} \text {-bacterial } \\
\text { infections, followed by tuberculosis }\end{array}$ \\
\hline $\begin{array}{l}\text { Orsini et al } \\
\text { Brooklyn }\end{array}$ & $\begin{array}{l}\text { single-center, } \\
\text { prospective, and } \\
\text { observational } \\
\text { study }\end{array}$ & $\begin{array}{l}\text { HIV-infection and respiratory } \\
\text { failure admitted to the ICU } \\
\text { from December } 1,2011 \text {, to } \\
\text { February } 28,2013 \text {, }\end{array}$ & $\begin{array}{l}\text { bacterial pneumonia } \\
\text { Pneumocystis jirovecii pneumonia } \\
\text { vancomycin-resistant Enterococcus (VRE) bacteremia } \\
\text { lung abscess }\end{array}$ \\
\hline
\end{tabular}

and this may often require invasive interventions like bronchoscopy to get a bronchoalveolar sample.

Appropriate sample collection may be taken for staining and cultures (sputum/bronchoscopic lavage or non-directed BAL in intubated patients Table 2). Sample collection should be done as early as possible, preferably within 1 hour and a broad spectrum antibiotic to cover gram-negative organisms may be added empirically. In case there is a delay of collecting the sample, the antibiotics should be administered as fast as possible. Sputum samples should be sent for gram staining, culture, and also special stains for pneumocystis. Cartridge based nucleic acid amplification test (CBNAAT) of samples is beneficial in the early and rapid diagnosis of MTB and multi-drug resistant tuberculosis (MDRTB). In con-

Table 2: Tests On Sputum/Broncho-Alveolar Lavage Fluid

\begin{tabular}{|c|c|}
\hline Cytology & Total and differential cell counts \\
\hline Microbiology & Gram stain for Bacterial pathogens \\
\hline Staining & $\begin{array}{l}\mathrm{KOH} / \text { calcofluor white preparation for fungal } \\
\text { pathogens } \\
\text { Ziehl-Neelson for Mycobacteria } \\
\text { Special stains such as Silver methenamine } \\
\text { for Pneumocystis jerovecii pneumonia }\end{array}$ \\
\hline Cultures & $\begin{array}{l}\text { Aerobic culture for bacteria, MGIT for } \\
\text { Mycobacterium tuberculosis, fungal culture }\end{array}$ \\
\hline $\begin{array}{l}\text { Quantitative or } \\
\text { semiquantitative } \\
\text { cultures or } \\
\text { molecular assays }\end{array}$ & $\begin{array}{l}\text { Pneumocystis jerovecii } \\
\text { Nocardia } \\
\text { Mycobacterium tuberculosis } \\
\text { Toxoplasma gondii } \\
\text { Strongyloides stercoralis } \\
\text { Legionella pneumophila } \\
\text { Cryptococcus neoformans } \\
\text { Histoplasma capsulatum } \\
\text { Mycoplasma pneumoniae } \\
\text { Influenza A and B viruses } \\
\text { Respiratory syncytial virus }\end{array}$ \\
\hline
\end{tabular}

cordance with the surviving sepsis guidelines, we also recommend measuring lactate at baseline.

Table 3: Risk factors for Pseudomonas and Staphylococcal infections

\begin{tabular}{|c|c|}
\hline Risk factors for $P$. aeruginosa & $\begin{array}{l}\text { Risk factors for methicillin- } \\
\text { resistant S. aureus }\end{array}$ \\
\hline $\begin{array}{l}\text { Advanced immunosuppression/ } \\
\text { full blown AIDS (CD4 count } \leq 50 \\
\text { cells/mm3) } \\
\text { underlying structural lung disease } \\
\text { such as bronchiectasis } \\
\text { Profound neutropenia } \\
\text { Treatment with long term } \\
\text { corticosteroids } \\
\text { Severely malnourished patients } \\
\text { Those residing in nursing homes/ } \\
\text { health care facilities or who had } \\
\text { recent hospitalizations in the last } \\
3 \text { months. } \\
\text { Patients on chronic hemodialysis }\end{array}$ & $\begin{array}{l}\text { Recent influenza infection; } \\
\text { IV drug abusers } \\
\text { Severe, bilateral, necrotizing } \\
\text { pneumonia } \\
\text { Recent head injury } \\
\text { Patients on chronic } \\
\text { hemodialysis }\end{array}$ \\
\hline
\end{tabular}

The recommendations regarding antibiotic therapy in HIV are based on studies in both ICU and Non-ICU patients admitted with community-acquired pneumonia (Table 4). In a Dutch trial-CAP-START, among patients admitted to inpatient wards for CAP, $\beta$-lactam, and macrolide combination therapy was associated with increased mortality - as compared with fluoroquinolone monotherapy. However, the cohort group had a very low incidence of atypical infections. Studies from Switzerland that compared $\beta$-lactam monotherapy to combination therapy with a $\beta$-lactam plus a macrolide found a nonsignificant trend of clinical stability in the combination group. A meta-analysis of $\beta$-lactam-macrolide combination therapy suggested that the combination was associated with reduced mortality compared with beta-lactam monotherapy. In view of the paucity of literature and 
unknown efficacy of monotherapy, the expert committee felt that these patients should receive broad-spectrum combination therapy rather than monotherapy.

After starting on initial broad-spectrum antibiotics, once the culture reports are available, the antibiotic therapy should be de-escalated as quickly as possible. Antibiotic de-escalation reduces the possibility of adverse drug effects, treatment costs and reduces the incidence of drug resistance. Parenteral antibiotics can be changed to oral route once clinical stability is attained. Suggested criteria for clinical stability include oral temperature $<37.8^{\circ} \mathrm{C}$, heart rate $<100$ beats /minute, respiratory rate $<24$ breaths/minute, systolic blood pressure $\geq 90 \mathrm{~mm}$ $\mathrm{Hg}$, and room air oxygen saturation $>90 \%$ or partial pressure of oxygen in arterial blood $\left(\mathrm{PaO}_{2}\right)>60 \mathrm{~mm}$ $\mathrm{Hg}$. De-escalation is safe in patients hospitalized with CAP including severe CAP. ${ }^{12-14}$ Antibiotics need to be given for a minimum of 5 days of treatment and may be stopped in case patients remain afebrile for 48 to 72 hours and are clinically stable. A longer duration of treatment might be required in case of metastatic foci of infection, or infection with drug-resistant bacteria such as MRSA or drug-resistant gram-negative bacteria. ${ }^{15,16}$

\section{HIV Positive Patients Presenting with Suspected Bloodstream Infections or Sepsis of Unknown Origin}

\section{Evidence Statements}

- In the presence of sepsis or septic shock, we recommend following the surviving sepsis guidelines similar to the management of other patients with sepsis (UPP, A).

- In the absence of septic shock or absence of risk factors for Pseudomonas a monotherapy with a third-generation cephalosporin or a cephalosporin, the $\beta$-lactamase inhibitor is sufficient (II, A)

- In more severe disease states, such as in the presence of organ dysfunction or septic shock-a combination of broad-spectrum antibiotics may be used for initial empiric therapy (III, A).

- Combination therapy is discouraged in the absence of ongoing shock (I, B)

- Empiric gram-positive coverage is suggested for those who have risk factors for MRSA (UPP, A)

- Anti-fungal agents may be considered only if there is no clinical improvement or there is clinical deterioration even after 72 hours of appropriate empirical antibiotics therapy and CD4 counts $<200 / \mathrm{mm}^{3}$ (II, A).

- We recommend against the use of empirical antifungal therapy (II, A)

- Those with CD4 $<100 / \mathrm{mm}^{3}$ are at high risk for disseminated tuberculosis and hence, need to be worked up for tuberculosis - including blood cultures for tuberculosis (I, B).

- We recommend against empirical anti-tubercular therapy (ATT). In cases of proven mycobacteremia, ATT may be started as per national guidelines or in consult with the ID specialist (I, A).

Table 4: Results of comparison of various antibiotic regimen in Community Acquired Pneumonia.

\begin{tabular}{llll}
\hline Author/ Country & Design & Study population & Conclusion \\
\hline $\begin{array}{l}\text { Postma DF, } \\
\text { Netherlands }^{8}\end{array}$ & randomized, & Hospitalized patients & $\begin{array}{l}\text { Among patients with clinically suspected CAP, empirical } \\
\text { treatment with beta-lactam monotherapy was non-inferior } \\
\text { crossover trial }\end{array}$ \\
& & (non-ICU) & $\begin{array}{l}\text { a beta-lactam-macrolide combination or fluoroquinolone } \\
\text { monotherapy with regard to 90-day mortality. }\end{array}$
\end{tabular}

Lee $\mathrm{JS}^{9} \quad$ Review $\quad$ adults hospitalized with community-acquired pneumonia
Nie $\mathrm{W}^{10}$

Garin N Switzerland ${ }^{11}$
Meta-analysis Included four prospective cohort studies and 12 retrospective cohort studies

multicenter, 580 immunocompetent non blinded, adult patients with noninferiority, moderately severe CAP
A cluster randomized trial demonstrated an absolute adjusted difference of $2.5 \%$ in 90 -day mortality favoring $\beta$-lactam monotherapy over $\beta$-lactam plus macrolide combination therapy.

Another randomized trial found an absolute difference of $7.6 \%$ in the attainment of clinical stability on day 7 favoring $\beta$-lactam plus macrolide combination therapy over monotherapy with $\beta$ lactam.

Six observational studies found that $\beta$-lactam plus macrolide combination therapy was associated with relative reductions of $26 \%$ to $68 \%$ in short-term mortality

3 observational studies reported that fluoroquinolone monotherapy was associated with relative reductions of $30 \%$ to $43 \%$ in mortality compared with $\beta$-lactam monotherapy.

In comparison with beta-lactam monotherapy, beta-lactam macrolide dual therapy reduces the risk of mortality in patients with CAP

In patients hospitalized for moderately severe CAP, $\beta$-lactam monotherapy had delayed clinical stability with monotherapy and hence cannot be considered non inferior. 
- Lateral Flow urine LipoArabinomannan Assay (LF-LAM) may be used to assist in the diagnosis of TB only in HIV positive adult in-patients with signs and symptoms of TB (pulmonary and/or extrapulmonary) who have a CD 4 cell count $<100$ cells $/ \mathrm{mm}^{3}$, or HIV positive patients who are seriously ill regardless of CD4 count or with unknown CD4 count (II, B).

- LF-LAM should not be used as a screening test for TB (III, A).

\section{Evidence Summary}

Bloodstream infections are common in AIDS patients. As with respiratory failure cases, most of the data is from western countries (Table 5). Except for blood stream infections (BSI) caused by tuberculosis, the data from India is scarce. The common organisms seem to be non-typhoid Salmonellae, Streptococcus pneumoniae, Escherichia coli, Staphylococcus aureus, and coagulase-negative Staphylococci. M. Tuberculosis is not rare if CD4 count $100 / \mathrm{mm}^{3}$. The antibiotics policy for these patients remains the same as mentioned in international guidelines for sepsis. ${ }^{17,18}$

\section{HIV positive patient presenting with signs of CNS infection in ICU}

\section{Evidence Statements}

- We recommend brain imaging (preferably MRI) and/ or fundoscopy for ruling out raised intra cranial pressure (ICP). If possible the opening pressure should be measured, and physical characteristics such as cerebrospinal fluid (CSF) appearance should be noted (UPP, B)

- Alumbar puncture should be performed for microbiological and biochemical assay including gram stain, India ink stain, aerobic culture, protein, sugar, Adenosine Deaminase (ADA) levels, lactate levels, and cells.

- We suggest a detailed workup for Tuberculosis including an assay for CBNAAT, Mycobacteria growth indicator tube (MGIT) culture, CSF analysis, ADA. (UPP, B)

- In immunocompromised host with relevant clinicoradiological findings and CNS symptoms, additional samples may be sent for $T$. gondii (IgG antigen and /or polymerase chain reaction (PCR), cryptococcal antigen, Mycobacterium tuberculosis (PCR), and common viruses such as Epstein-Barr Virus DNA (EBV) and JC Virus (JCV) along with work up for bacterial culture (UPP, A).

Table 5: Common organisms isolated from the bloodstream in patients with HIV

\begin{tabular}{|c|c|c|c|c|}
\hline $\begin{array}{l}\text { Reference (First } \\
\text { Author, Year) }\end{array}$ & $\begin{array}{l}\text { Study Location and } \\
\text { Time Frame }\end{array}$ & Study Design & Primary Inclusion Criteria & $\begin{array}{l}\text { Main Isolates in HIV Patients (\% } \\
\text { of Bacterial Isolates in HIV) }\end{array}$ \\
\hline Grant, $1997^{19}$ & $\begin{array}{l}\text { Ivory Coast, } \\
1995\end{array}$ & $\begin{array}{l}\text { Prospective } \\
\text { Observational Study }\end{array}$ & $\begin{array}{l}\text { Admission to the infectious } \\
\text { disease unit }\end{array}$ & $\begin{array}{l}\text { Nontyphoid salmonella } 23 \text { (59), } \\
\text { E. coli } 6 \text { (15), S. pneumoniae } 4 \\
(10)\end{array}$ \\
\hline Hung, $1998^{20}$ & Taiwan,1994-1996 & $\begin{array}{l}\text { Prospective } \\
\text { Observational Study }\end{array}$ & $\begin{array}{l}\text { Fever }\left(\geq 38^{\circ} \mathrm{C}\right) \text { in HIV- } \\
\text { infected patients admitted to } \\
\text { AIDS unit }\end{array}$ & $\begin{array}{l}\text { Non typhoid salmonella } 24 \\
(80), \text { S. aureus } 3(8), \text { Klebsiella } \\
\text { pneumoniae } 2(5), \text { E. coli } 2(5), \\
\text { P. aeruginosa } 2(5)\end{array}$ \\
\hline Manfredi, $1999^{21}$ & $\begin{array}{l}\text { Italy, 1994-1995, } \\
1997-1998\end{array}$ & $\begin{array}{l}\text { Retrospective } \\
\text { study }\end{array}$ & $\begin{array}{l}\text { HIV patients admitted to the } \\
\text { Hospital }\end{array}$ & $\begin{array}{l}\text { Gram-positive catalase-positive } \\
\text { cocci }\end{array}$ \\
\hline Mayanja, $2010^{22}$ & $\begin{array}{l}\text { Rural Uganda, } \\
\text { 1996-2007 }\end{array}$ & Cohort study & $\begin{array}{l}\text { Fever }\left(\geq 38^{\circ} \mathrm{C}\right) \text { with no } \\
\text { detectable malaria Parasites }\end{array}$ & $\begin{array}{l}\text { S. pneumoniae } 68 \text { (43), NTS } 42 \\
\text { (26), CoNS } 10 \text { (6), E. coli } 9 \text { (6) }\end{array}$ \\
\hline Meremo, $2012^{23}$ & $\begin{array}{l}\text { Urban Tanzania, } \\
2011\end{array}$ & $\begin{array}{l}\text { Prospective } \\
\text { Observational Study }\end{array}$ & $\begin{array}{l}\text { Hospital admission with } \\
\text { fever (axillary temperature } \\
>37.5^{\circ} \mathrm{C} \text { ) }\end{array}$ & Nontyphoid salmonella $12(75)$ \\
\hline $\begin{array}{l}\text { Mootsikapun } \\
2007^{24}\end{array}$ & $\begin{array}{l}\text { Urban Thailand, } \\
\text { 1996-2001 }\end{array}$ & Retrospective study & $\begin{array}{l}\text { Positive blood culture } \\
\text { (including fungi and } \\
\text { mycobacteria) }\end{array}$ & $\begin{array}{l}\text { NTS } 82(61), \text { S. aureus } 13(20) \text {, } \\
\text { Enterobacter spp } 11(8)\end{array}$ \\
\hline Muyanja, $2011^{25}$ & $\begin{array}{l}\text { Uganda, 1995- } \\
2008\end{array}$ & Cohort study- & HIV infected & $\begin{array}{l}\text { S. pneumoniae } 103 \text { (42), NTS } 66 \\
(27) \text {, E. coli } 18 \text { (7) }\end{array}$ \\
\hline VarmaJK, $2010^{26}$ & thailand & prospective-2006-2008 & $\begin{array}{l}\text { Outpatients diagnosed } \\
\text { with HIV regardless of the } \\
\text { presence or absence of } \\
\text { symptoms or prior suspicion } \\
\text { of clinical illness }\end{array}$ & $\begin{array}{l}\text { M.TB } 31(54 \%) \text {, fungi [13 (22\%)], } \\
\text { and bacteria [9 }(16 \%)] \text {. }\end{array}$ \\
\hline Gopinath $^{27}$ & $\begin{array}{l}\text { India } \\
\text { 2005-2006 }\end{array}$ & Prospective study & $\begin{array}{l}\text { Hospitalized patients } \\
\text { with HIV-and suspected } \\
\text { tuberculosis }\end{array}$ & М.ТВ $30 \%$ \\
\hline Ramachandran ${ }^{28}$ & India & Prospective control study & $\begin{array}{l}\text { Hospital admission with a } \\
\text { diagnosis of HIV }\end{array}$ & $4 \%$ МTB \\
\hline
\end{tabular}


- For Cryptococcal Meningitis, a paired sample of both serum and CSF should be sent for S. Cryptococcal antigen assay and CSF Cryptococcal antigen (UPP, A).

- In patients presenting with features of raised ICP and intracranial mass lesions, toxoplasma also needs to be considered. We recommend CSF analysis for IgG antibodies against Toxoplasma antibodies as it has a good negative predictive value in ruling out infections (UPP, A).

- For a patient coming to ICU with altered CNS function and suspicion of meningitis, we recommend a thirdgeneration cephalosporin- known to penetrate the blood-brain barrier - at higher doses, e.g., Ceftriaxone 2 gm BD intravenously (I, A).

- We suggest the addition of vancomycin empirically to the initial treatment regime (I, B).

- We recommend de-escalating antibiotics after culture reports are available (I, A).

- In patients above 50 years of age, we suggest the use of additional ampicillin at high doses of 2 gm every 6th hourly (I, B).

- In very young infants of age $<1$ month, we suggest Ampicillin plus cefotaxime or ampicillin plus an aminoglycoside as the initial management (I, B).

- For Cryptococcal meningitis, we recommend induction therapy followed by consolidation therapy for 2 months. In patients with severe disease, and low CD4 counts we recommend maintenance therapy for atleast a year (II, A).

- The preferred induction therapy recommended is Liposomal amphotericin B (3 to $5 \mathrm{mg} / \mathrm{kg}$ IV daily) plus flucytosine $(100 \mathrm{mg} / \mathrm{kg}$ per day orally in four divided doses) for a minimum of two weeks. If flucytosine is not available, fluconazole (800 mg daily orally) with Amphotericin B should be given for a minimum of two weeks (I, B).

- In view of the risk of serious adverse effects, we suggest the use of liposomal amphotericin B instead of amphotericin deoxycholate, if cost is not an issue (II, B).

- We recommend Amphotericin B deoxycholate (0.7 $1 \mathrm{mg} / \mathrm{kg} /$ day IV daily) be used if liposomal amphotericin is not available and the risk of renal dysfunction is low. (I, A)

- Consolidation therapy with fluconazole at a dose of $400 \mathrm{mg}$ orally daily for a minimum of eight weeks is recommended (I, A).

- Maintenance therapy: At the completion of eight weeks, fluconazole $200 \mathrm{mg}$ daily should be continued for long-term suppression for a minimum of one year, if CD4 count $>100$ cells $/ \mathrm{mm}^{3}$ (II, B).
- Secondary prophylaxis should be reinitiated if the CD4 count decreases again to $<100$ cells $/ \mathrm{mm}^{3}$ (III, A)

- Corticosteroids and mannitol have been shown to be ineffective in managing ICP, and we recommend against the routine use of these agents in cryptococcal meningitis (III, A). In the case of IRIS, corticosteroids should be administered to manage severe central nervous system immune reconstitution inflammatory syndromes. (I, A)

Immediate ART in the setting of Cryptococcal meningitis may increase the risk of serious IRIS, a short delay (4-8 weeks) before initiating ART may be necessary. ${ }^{29,30}$

\section{Empiric therapy for suspected CNS toxoplasmosis}

\section{Evidence Statements}

- We recommend a combination of pyrimethamine plus sulfadiazine plus leucovorin in patients with suspected toxoplasmosis (Sulfadiazine $1000 \mathrm{mg}$ four times daily among patients $<60 \mathrm{~kg}$ or $1500 \mathrm{mg}$ four times daily among patients $\geq 60 \mathrm{~kg}$, Pyrimethamine $200 \mathrm{mg}$ loading dose followed by $50 \mathrm{mg}$ daily among patients $<60 \mathrm{~kg}$ or $75 \mathrm{mg}$ daily among patients $\geq 60$ $\mathrm{kg}$, Leucovorin 10 to $25 \mathrm{mg}$ daily) (I, A).

- Pyrimethamine plus clindamycin plus leucovorin is the preferred alternative regimen for patients with TE who cannot tolerate sulfadiazine or do not respond to first-line therapy (I, A).

- If pyrimethamine is unavailable or there is a delay in obtaining it, TMP-SMX should be utilized in place of pyrimethamine-sulfadiazine or pyrimethamineclindamycin (I, B).

- Acute therapy for Toxoplasmosis should be continued for at least 6 weeks if there is a clinical and radiologic improvement (II, B).

- Adjunctive corticosteroids such as dexamethasone may be administered to patients to treat a mass effect associated with focal lesions or associated edema (III, B)

\section{Management of Tuberculous meningitis or CNS Tuberculoma}

- The management remains the same as in CNS tuberculosis in an immunocompetent individual with 2 months of an intensive regimen with four drugs and 7 to 9 months of continuation phase (total 9-11 months) (I, A)

- If not already on ART, ART should be initiated after 8 weeks of intensive phase, regardless of CD4 count (I, A). 
- Systemic corticosteroids are indicated to prevent/ manage IRIS. Initiate 0.5 to $1 \mathrm{mg} / \mathrm{kg}$ of prednisone daily, and then taper the dose over two to six weeks. (I, A) A good alternative is to administer dexamethasone, tapered over 2 to 6 weeks. (I, A)

- We suggest initiation of antituberculous therapy on the basis of strong clinical suspicion of CNS tuberculosis. Treatment should not be delayed until proof of infection has been obtained (I, B).

\section{Evidence Summary}

Management of treatment-naïve HIV-infected patients with TB is especially challenging in areas with high rates of coinfection. Initiation of antiretroviral therapy may be complicated by the immune reconstitution inflammatory syndrome (IRIS), which can manifest as reactivation of latent $\mathrm{TB}$, the progression of active $\mathrm{TB}$ disease, or clinical deterioration in patients previously improving on antituberculous therapy.

The most important factor in determining the differential diagnosis is the degree of immunosuppression in the patient.

In patients with CD4 cell counts $>500 / \mathrm{mm}^{3}$, benign and malignant brain tumors and metastases predominate, as in immunocompetent hosts.

In moderately immunosuppressed patients with CD4 cell counts from 200 to $500 / \mathrm{mm}^{3}$, HIV-associated cognitive and motor disorders are common but usually, do not present with focal lesions.

In severely immunosuppressed patients with CD4 cell counts $<200 / \mathrm{mm}^{3}$, CNS mass lesions are most common. The most likely diagnostic considerations include opportunistic infections (Toxoplasma encephalitis, primary CNS lymphoma, progressive multifocal leukoencephalopathy, HIV encephalopathy, and CMV encephalitis) and AIDS-associated tumors, such as primary central nervous system lymphoma.

In addition, multiple etiologies can coexist in an immunosuppressed individual. ${ }^{31-33}$

Patients who are not under medical supervision, or those who are not aware of their HIV status, may present with their first opportunistic infection in the central nervous system. The clinical manifestations and the diagnostic possibilities are similar to those seen in before the introduction of potent antiretroviral therapy (ART) era. However, the effect of prophylaxis for Pneumocystis and the use of ART may alter the clinical spectrum of disease and the diagnostic considerations in patients who are taking medications. ${ }^{34-35}$ In a patient presenting with CNS symptoms/ altered mentation, noninfectious and infectious causes need to be ruled out. A practical approach is shown in the flowchart.

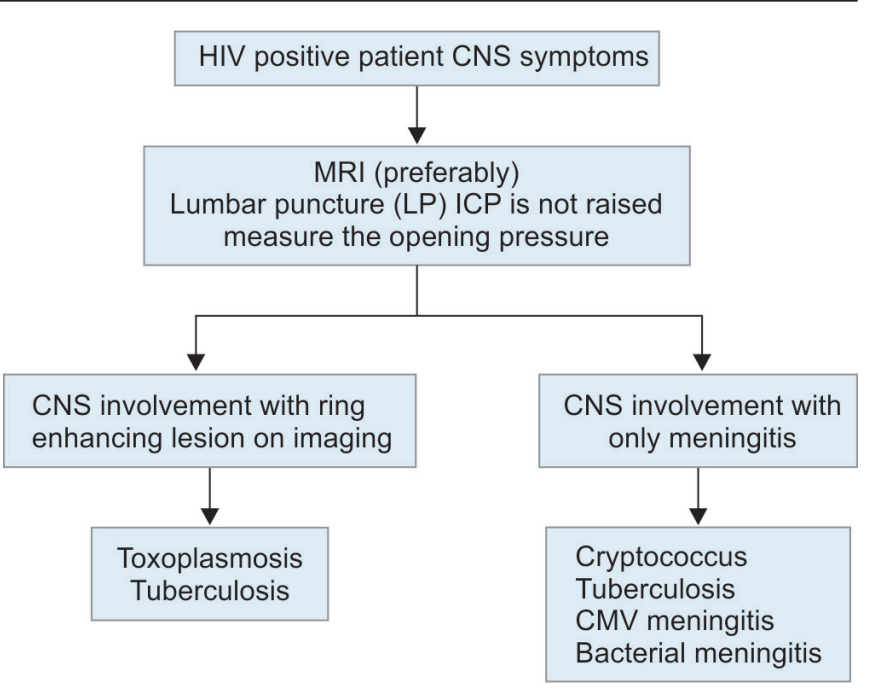

Drug interactions need to be considered when starting treatment of an HIV patient already on HAART with drugs such rifampicin and clarithromycin. Drug resistance is an important factor that has to be considered in these patients hence whenever possible, the expert committee feels that treatment of suspected TB should be initiated only after a microbiological diagnosis and in liaison with an infectious disease expert.

\section{REFERENCE}

1. Ganesan A, Masur H. Critical care of persons infected with the human immunodeficiency virus. Clin Chest Med. 2013;34:307-23.

2. Di Pasquale MF, Sotgiu G, Gramegna A, Radovanovic D, Terraneo F, Reyes LF, Rupp J, et al. Prevalence and Etiology of Community-acquired Pneumonia in Immunocompromised Patients. https:/ /academic.oup.com/cid/advancearticle/doi/10.1093/cid/ciy723/5078600-last accessed on $26^{\text {th }}$ December 2018

3. Chiang HH, Hung CC, Lee CM, Chen HY, Chen MY, Sheng WH, Hsieh SM. et al. Admissions to intensive care unit of HIV-infected patients in the era of highly active antiretroviral therapy: etiology and prognostic factors. Crit Care. 2011;15:R202.

4. Barbier F, Coquet I, Legriel S, Pavie J, Darmon M, Mayaux J, Molina JM, et al. Etiologies and outcome of acute respiratory failure in HIV-infected patients. Intensive Care Med. 2009;35: 1678-86.

5. Alves C, Nicolás JM, Miró JM, Torres A, Agustì C, Gonzalez J, Raño A, et al. Reappraisal of the aetiology and prognostic factors of severe acute respiratory failure in HIV patients. Eur Respir J. 2001;17:87-93.

6. Lee KY, Ho CC, Ji DD, Lee CM, Tsai MS, Cheng AC, Chen $\mathrm{PY}$, et al. Etiology of pulmonary complications of human immunodeficiency virus-1-infected patients in Taiwan in the era of combination antiretroviral therapy: a prospective observational study. J Microbiol Immunol Infect. 2013;46:433-40.

7. Orsini J, Ahmad N, Butala A, Flores R, Tran T, Llosa A FE. Etiology and Outcome of Patients with HIV Infection and Respiratory Failure Admitted to the Intensive Care Unit. Interdiscip Perspect Infect Dis. 2013:732421.

8. Postma DF, van Werkhoven $\mathrm{CH}$, van Elden LJ, Thijsen SF, Hoepelman AI, Kluytmans JA, Boersma WG, et al. BMC-SSG. 
Antibiotic Treatment Strategies for Community-Acquired Pneumonia in Adults. N Engl J Med. 2015;372:1312-23.

9. Lee JS, Giesler DL, Gellad WF, Fine MJ. Antibiotic Therapy for Adults Hospitalized With Community-Acquired Pneumonia. JAMA. 2016;315:593-602.

10. Nie W, Li B, Xiu Q. -Lactam/macrolide dual therapy versus -lactam monotherapy for the treatment of communityacquired pneumonia in adults: a systematic review and meta-analysis. J Antimicrob Chemother. 2014;69:1441-6.

11. Garin N, Genné D, Carballo S, Chuard C, Eich G, Hugli O, Lamy $\mathrm{O}$, et al. -Lactam monotherapy vs -lactam-macrolide combination treatment in moderately severe communityacquired pneumonia: a randomized noninferiority trial. JAMA Intern Med. 2014;174:1894-901.

12. Viasus D, Simonetti AF, Garcia-Vidal C, Niubó J, Dorca J, Carratalà J. Impact of antibiotic de-escalation on clinical outcomes in community-acquired pneumococcal pneumonia. J Antimicrob Chemoth. 2017;72:547-53.

13. Carugati M, Franzetti F, Wiemken T, Kelly R, Peyrani P, Blasi F, Ramirez J et al. De-escalation therapy among bacteraemic patients with community-acquired pneumonia. Clin Microbiol Infect. 2015;21:936.e11-8.

14. Yamana H, Matsui H, Tagami T, Hirashima J, Fushimi K, Yasunaga $\mathrm{H}$. De-escalation versus continuation of empirical antimicrobial therapy in community-acquired pneumonia. J Infect. 2016;73:314-25.

15. Uranga A, España PP, Bilbao A, Quintana JM, Arriaga I, Intxausti M, et al. Duration of Antibiotic Treatment in CommunityAcquired Pneumonia. JAMA Intern Med. 2016;176:1257-65.

16. Mandell LA, Wunderink RG, Anzueto A, Bartlett JG, Campbell GD, Dean NC, Dowell SF, et al. Infectious Diseases Society of America/American Thoracic Society Consensus Guidelines on the Management of Community-Acquired Pneumonia in Adults. Clin Infect Dis. 2007;44:S27-72.

17. Rhodes A, Evans LE, Alhazzani W, Levy MM, Antonelli M, Ferrer R, Kumar A, et al. Surviving Sepsis Campaign: International Guidelines for Management of Sepsis and Septic Shock: 2016. Intensive Care Med. 2017;43:304-77.

18. Levy MM, Evans LE Rhodes A. The Surviving Sepsis Campaign Bundle: 2018 Update. Crit Care Med. 2018;46:997-1000.

19. Grant AD, Djomand G, Smets P, Kadio A, Coulibaly M, Kakou A, Maurice C, et al. Profound immunosuppression across the spectrum of opportunistic disease among hospitalized HIV-infected adults in Abidjan, Côte d'Ivoire. AIDS. 1997;11:1357-64.

20. Hung CC, Hsueh PR, Hsieh SM, Liu CJ, Chen MY, Luh KT. Bacteremia and fungemia in patients with advanced human immunodeficiency virus (HIV) infection in Taiwan. J Formos Med Assoc. 1998;97:690-7.

21. Manfredi R, Nanetti A, Ferri M, Chiodo F. HIV-associated non-mycobacterial sepsis-bacteraemia, before and during the highly active antiretroviral therapy era. AIDS . 1999;13:1274-6.

22. Mayanja BN, Todd J, Hughes P, Van der Paal L, Mugisha JO, Atuhumuza E, Tabuga $\mathrm{P}$, et al. Septicaemia in a populationbased HIV clinical cohort in rural Uganda, 1996-2007: inci- dence, aetiology, antimicrobial drug resistance and impact of antiretroviral therapy. Trop Med Int Heal. 2010;15:697705 .

23. Meremo A, Mshana SE, Kidenya BR, Kabangila R, Peck R, Kataraihya JB. High prevalence of Non-typhoid salmonella bacteraemia among febrile HIV adult patients admitted at a tertiary Hospital, North-Western Tanzania. Int Arch Med. 2012;5:28.

24. Mootsikapun P. Bacteremia in adult patients with acquired immunodeficiency syndrome in the northeast of Thailand. Int J Infect Dis. 2007;11:226-31.

25. Muyanja SZ, Larke N, Rutebarika D, Kaddu I, Nakubulwa S, Levin J, Grosskurth H, et al. Decreasing trends of bacteraemia among HIV-infected Ugandan adults: incidence, aetiology, clinical outcomes and effect of antiretroviral therapy in a semiurban setting (2000-2008). Trop Med Int Heal. 2011;16:756-65.

26. Varma JK, McCarthy KD, Tasaneeyapan T, Monkongdee $\mathrm{P}$, Kimerling ME, Buntheoun E, Sculier D, et al. Bloodstream infections among HIV-infected outpatients, Southeast Asia. Emerg Infect Dis. 2010;16:1569-75.

27. Gopinath k, Kumar S, Singh S. Prevalence of mycobacteremia in Indian HIV-infected patients detected by the MB/BacT automated culture system Medicinal Orchids of Arunachal Pradesh; Micro propagation, Phytochemical Investigation and Biological Activity Evaluation View project. Eur J Clin Microbiol. 2008;27:423-31.

28. Ramachandran R, Swaminathan S, Somasundaram S, Asgar VN PP, Paramasivan CN. Mycobacteremia in tuberculosis patients with HIV infection. Ind J Tubrculosis. 2002;50: 29-31.

29. Boulware DR, Meya DB, Muzoora C, Rolfes MA, Huppler Hullsiek K, Musubire A, Taseera K, et al. Timing of antiretroviral therapy after diagnosis of cryptococcal meningitis. N Engl J Med. 2014;370:2487-2498.

30. Panel on Antiretroviral Guidelines for Adults and Adolescents. Guidelines for the Use of Antiretroviral Agents in Adults and Adolescents Living with HIV. Department of Health and Human Services. Available at http:/ /www.aidsinfo.nih.gov/ContentFiles/ AdultandAdolescentGL.pdf./ Last accessed on $26^{\text {th }}$ December 2018.

31. Stenzel W, Pels H, Staib P, Impekoven P, Bektas N, Deckert M.. Concomitant manifestation of primary CNS lymphoma and Toxoplasma encephalitis in a patient with AIDS. J Neurol 2004; 251:764-66.

32. Gildenberg PL, Gathe JC Jr, Kim JH.. Stereotactic biopsy of cerebral lesions in AIDS. Clin Infect Dis. 2000;30:491-9.

33. Gheuens S, Cheeseman SH, Koralnik IJ.. Hidden in plain view: emergence of progressive multifocal leukoencephalopathy after treatment of CNS toxoplasmosis. Acta Neurol Belg. 2011;111:217-19.

34. Collazos J. Opportunistic Infections of the CNS in Patients with AIDS. CNS Drugs. 2003;17:869-87.

35. Tan IL, Smith BR, von Geldern G, Mateen FJ, McArthur JC. HIV-associated opportunistic infections of the CNS. Lancet Neurol. 2012;11:605-17. 


\section{PART 4. INDIAN ANTIMICROBIAL PRESCRIPTION GUIDELINES FOR PATIENTS WITH CONGENITAL AND ACQUIRED HYPOSPLENISM/ASPLENIA}

Patients with congenital and acquired hyposplenism/ asplenia are prone to specific infections and are at increased risk of severe sepsis. Although the incidence of septicemia remains low, the risk for overwhelming postsplenectomy infection (OPSI) remains higher than in the general population. ${ }^{1}$ Majority of the overwhelming postsplenectomy infection (OPSI) is caused by encapsulated bacteria such as Streptococcus pneumonia, Haemophilus influenza, and Neisseria meningitides although other infections can also occur. ${ }^{2,3}$ The disease starts as a minor flu-like illness and rapidly evolves into a fulminant course of hypoglycemia, metabolic acidosis, dyselectrolytemia, disseminated intravascular coagulation (DIC), shock, coma and death within 24 to 48 hours. ${ }^{4}$ OPSI usually occurs within the first two years after splenectomy but may also occur later and has a mortality rate of 50 to $70 \%$ despite aggressive therapy. ${ }^{2}$ In view of the severe progression and high mortality of OPSI, stress has been given for early aggressive treatment as well as immunization of patients with splenectomy and thereby preventing OPSI.

\section{Evidence Statements}

- If an asplenic/hyposplenic patient is suspected to have sepsis we recommend administration of IV ceftriaxone before transferring the patient to a higher center (II, A).

- We recommend that all patients with Overwhelming Post-Splenectomy Infection (OPSI) be treated in the ICU. (UPP, A)

- We recommend empiric antibiotic therapy for asplenic patients with a combination of ceftriaxone and vancomycin. (I, A)

- In case of allergy to -lactams, we recommend vancomycin with aztreonam or fluoroquinolones in adults. Do not delay the administration of antibiotics, be prepared to treat the reaction. (UPP, A)

- We recommend adding clarithromycin or erythromycin in case of respiratory symptoms (III, A).

- We recommend empiric therapy with IV Cefotaxime + vancomycin + ampicillin if the patient age $<2$ months: (III, A)

- All febrile asplenic patients should be screened for malaria with peripheral smears. Start artesunate-based antimalarial therapy, if the history is suggestive of Malaria (UPP, A).

- If gram staining of peripheral blood smear shows gram-negative bacilli, we recommend the addition of antipseudomonal coverage to the therapy (III, A).

- We recommend that urine be checked for a urinary antigen for streptococcus pneumonia (II, A).
- We suggest RT-PCR test for simultaneous identification of 3 main encapsulated bacteria (Strep pneumonia, H. influenzae type B and N. meningitidis) (III, B).

- We recommend that all asplenic patients should receive immunization against encapsulated bacteria (S. pneumoniae, H. influenzae, and N. meningitidis) (I, A).

- Immunization against seasonal flu is recommended for patients over 6 months of age (I, A).

- We recommend that vaccination programs should be started no sooner than 14 days after splenectomy (I, A).

- If the patient is discharged before 15 days after splenectomy or angioembolization, where the risk to miss vaccination is deemed high, we suggest that patient be vaccinated before discharge (I, B).

- Antibiotic prophylaxis is indicated in patients for 1-2 years after splenectomy and lifelong for the patient had an episode of overwhelming infection or immunocompromised (II, B).

- We recommend self-administration of one dose of, in stock "pill in the pocket", prescribed antibiotics in the event of any sudden onset of unexplained fever, malaise, chills or other constitutional symptoms, when medical consultation not readily accessible within 2 hours (II, A).

- We suggest that any patient with sepsis having a risk factor for hyposplenia, the peripheral smear should be checked for Howell-Jolly bodies (II, B).

- We recommend formulation of Spleen registry (UPP, A).

\section{Evidence Summary}

Splenectomy is often indicated in patients with an underlying malignant or nonmalignant hematologic diseases or cases of splenic rupture following infection or trauma. Other causes of hyposplenia include auto infarction in subjects with sickle cell anemia and chronic graft-versushost disease after stem-cell transplantation, severe celiac disease, and untreated human immunodeficiency virus infection. ${ }^{5}$

Overwhelming post-splenectomy infection (OPSI) is defined as an infection, occurring more commonly after splenectomy (or in hyposplenic host) which evolves over a short time and produces severe symptoms, often with hypotension and a high mortality rate. ${ }^{6}$

Patients with hyposplenism due to splenectomy or hyposplenia are at an increased risk for invasive infections with encapsulated bacteria as Streptococcus pneumoniae, Haemophilus influenza type b, Neisseria meningitidis. ${ }^{2,7}$ These infections progress rapidly from a mild flu-like illness to fulminant sepsis and are associated with a high mortality rate of up to $50 \%$ despite maximal treatment. 
The lifetime risk of OPSI is assumed to be $5 \%$, and the highest frequency of these OPSIs is during the first 2 years after splenectomy. ${ }^{6-9}$ Patients with sickle cell anemia, thalassemia major or malignancies such as Hodgkin's lymphomas and non-Hodgkin's lymphomas have a higher risk for OPSI. Asplenic patients have a higher incidence of parasitemia, a delayed clearance of parasites after treatment or a severe or even fatal infection due to malaria. These patients are also at high risk for Babesiosis, and this might be confused with Plasmodium falciparum. ${ }^{2}$ These patients are at an increased risk of OPSI with Capnocytophaga canimorsus, if bitten by dogs and other animals and should receive adequate antibiotic coverage following such bites. ${ }^{10}$ Otherwise rare, Ehrlichiosis is also more severe in patients with asplenia/hyposplenia. ${ }^{2}$

OPSI should be considered as a medical emergency and mandates early recognition and aggressive management. These patients should be managed aggressively including immediate cultures and administration of a combination of antibiotics to cover all possible etiological agents. In areas where penicillin-resistant pneumococci are prevalent, other agents such as vancomycin, teicoplanin or rifampicin should be added to ceftriaxone as the initial empiric therapy. Gram stain of the peripheral blood or buffy coat will give an idea regarding the presence or absence of intraleukocytic bacteria. Antipseudomonal coverage should be added in case of high risk for Pseudomonas infection or peripheral blood growing GNB. The presence of intracellular bacteria within leukocytes should alert the clinician towards ehrlichiosis while the presence of parasites in RBC should alert for malaria or babesiosis. Once the blood cultures are positive antibiotics can be modified accordingly.

\section{REFERENCES}

1. Castagnola E, Fioredda F.Prevention of life-threatening infections due to encapsulated bacteria in children with hyposplenia or asplenia: a brief review of current recommendations for practical purposes. Eur J Haematol. 2003; 71:319-26.

2. Sumaraju V, Smith LG, Smith SM. Infectious complications in asplenic hosts. Infect Dis Clin North Am. 2001;15:551-65.

3. Davidson RN, Wall RA. Prevention and management of infections in patients without a Spleen. Clin Microbiol Infect. 2001; 7:657-60.

4. Evans DI. Postsplenectomy sepsis 10 years or more after operation. J Clin Pathol. 1985;38:309-11.

5. Leone G, Pizzigallo E. Bacterial Infections Following Splenectomy for Malignant and Nonmalignant Hematologic Diseases. Mediterr J Hematol Infect Dis. 2015;7:e2015057.

6. Morgan TL, Tomich EB. Overwhelming post-splenectomy infection (OPSI): a case report and review of the literature. J Emerg Med. 2012;43:758-63.

7. Waghorn DJ. Overwhelming infection in asplenic patients: current best practice preventive measures are not being followed. J Clin Pathol. 2001;54:214-218.

8. Brigden ML B. Overwhelming postsplenectomy infection still a problem. West J Med. 1992; 57:440-3.

9. Thomsen RW, Schoonen WM, Farkas DK, Riis A, Jacobsen J, Fryzek JP, Sørensen HT. Risk for hospital contact with infection in patients with splenectomy: a population based cohort study. Ann Intern Med. 2009;151:546-55.

10. Sawmiller CJ, Dudrick SJ, Hamzi M. Postsplenectomy Capnocytophaga canimorsus sepsis presenting as an acute abdomen. Arch Surg. 1998;133:1362-5. 
PART 5. PATIENTS WITH PRIMARY IMMUNE DEFICIENCY IN THE INTENSIVE CARE UNIT

Primary immunodeficiencies are a group of disorders that affect the development, function or both of the immune system. There are more than 300 disorders defined till date. The prevalence is approximately 1 in 10,000 live births ${ }^{1-3}$ Any patient admitted to ICU could be a potential PID patient.

\section{Diagnosis of PID}

\section{Evidence Statements}

- PID should be suspected when the following history / symptoms or signs are present (UPP, A)

1. Family history of sibling death

2. Four or more ear infections within 1 year

3. Two or more serious sinus infections or pneumonias within 1 year

4. Two or more months on antibiotics with little effect

5. Two or more deep-seated infections including septicemia

6. Persistent thrush in mouth or fungal infection on the skin

7. Infections in multiple anatomic locations

8. Increasing frequency and severity of infections with age

9. Recurrent serious infections with common pathogens

10. Serious infections with unusual pathogens

- We recommend that when PID is suspected, HIV infection should also be considered, and testing should be performed for HIV (UPP, A)

- We recommend that patient should be investigated for PID when:

1. In neonates, absolute lymphocyte count (ALC) of $<2000 / \mathrm{mm}^{3}$ in cord blood or an infant an ALC of $<4000 / \mathrm{mm}^{3}$

2. Severe hypogammaglobulinemia with $\operatorname{IgG}<1$ $50 \mathrm{mg} / \mathrm{dL}$.

3. Absolute lymphocyte count $<4000 / \mathrm{mm}^{3}$ (In nonchemotherapy setting)

4. Unusual organism picked up on microbiology

5. Unexplained neutropenia

- We recommend that Initial laboratory screening should include a complete blood count with differential counts (including absolute lymphocyte count, absolute neutrophil count, absolute monocyte count) and measurement of serum immunoglobulin and complement levels (UPP, A). We recommend severe combined immune deficiency (SCID) be considered as a pediatric emergency and attention be paid to absolute lymphocyte count, at all time in ICU. If the absolute lymphocyte count is less than normal for the age, we recommend to make immunology reference, use irradiated blood products, and avoid live vaccines till diagnosis is confirmed or ruled out (UPP, A).

- We recommend that patient be investigated for combined variable immuno-deficiency (CVID) when the patient has any of the following: (UPP, A)

1. Recurrent bacterial infections.

2. Serum IgG, IgM, IgA levels (at least two of the three) with a marked decrease (at least 2 SD below the mean for age)

3. The onset of immunodeficiency at more than 2 years of age.

4. The absence of isohemagglutinins and or poor response to vaccines.

- We recommend that immunology consult be obtained for these patients and the patient be investigated to diagnose specific form of immunodeficiency (UPP, A)

1. Lymphocyte subpopulations by flow cytometry (CD3, CD4, CD8, CD19, CD20, CD16 and CD56).

2. Naive T cells, Memory B cells, Memory T cells

3. T-cell response to mitogens.

4. Nitroblue tetrazolium-NBT test

5. Complement levels

6. Bone marrow and genetic tests

\section{Evidence Summary}

Diagnosis is often delayed since signs and symptoms such as bronchitis, pneumonia, sinusitis, and diarrhea are considered infection related without suspecting immunological process.

The absence of adenoid tissue in the nasopharynx or absence of the thymus should prompt suspicion of primary immunodeficiency (antibody or cellular/combined).

The presence of lymphocytopenia on complete blood count suggests a T-cell disorder, whereas a finding of neutropenia suggests a phagocytic disorder. Abnormal serum immunoglobulin levels suggest a B-cell disorder. Abnormalities on assay of the classic or alternative complement pathways suggest a complement disorder ${ }^{4}$ Abnormal values of lymphocyte count should also raise suspicion of PID (Table 1).

\section{Evidence Statement}

- We recommend appropriate cultures and PCRs; for organisms likely to cause infections pertinent to the conditions they are suffering from (UPP, A).

- An attempt should be made to identify the microorganisms directly or on PCRs as serological tests in infectious diseases could give false-negative results if there is an antibody defect (UPP, A).

- We recommend the use of Multiplex PCR to help diagnose infections (UPP, A) 
Indian Antimicrobial Prescription Guidelines in Critically III Immunocompromised Patients

Table 1: Absolute Lymphocyte count (ALC) nomogram Any value below the reference range should raise suspicion of PID

\begin{tabular}{lll}
\hline Age & $\begin{array}{l}\text { Lymphocytes (per } \\
m m 3)\end{array}$ & Range (per mm3) \\
\hline Neonatal & 4.8 & $0.7-7.3$ \\
$1-2$ month & 6.7 & $3.5-13.1$ \\
$2-5$ months & 5.9 & $3.7-9.6$ \\
5-9 months & 6.0 & $3.8-9.9$ \\
9-15 months & 5.5 & $2.6-10.4$ \\
15-24 months & 5.6 & $2.7-11.9$ \\
2-5 years & 3.3 & $1.7-6.9$ \\
5-10 years & 2.8 & $1.1-5.9$ \\
10-16 years & 2.2 & $1.0-5.3$ \\
$>16$ years & 1.8 & $1.0-2.8$ \\
\hline
\end{tabular}

\section{Evidence Summary}

Patients with PID commonly present with recurrent infections and invasive infections, atypical pathogens, partial response to antibiotics, failure to thrive, chronic diarrhea, fungal infections, unexplained skin rash, and family history. Infections such as Pneumonia and bronchiolitis, acute gastroenteritis, otitis media, and bacteremia in patients with an antibody, combined, and cellular deficiencies. Whereas viral infections meningitis, osteomyelitis, gastroenteritis is commonly seen in CVID. Children tend to have bacterial or fungal infections with unusual organisms or unusually severe and recurrent infections with common organisms. A family history of primary immunodeficiency disease is the strongest predictor of a person having this type of disease. ${ }^{5}$

The typical presentations of various PIDs by age of presentation and spectrum of infections.

- Combined T-cell and B-cell immunodeficiency (Presents early in life)

1. Bacteria: Campylobacter Listeria, Pyogenic bacteria, Mycobacteria

2. Viruses: RSV, EBV, Parainfluenza Virus

3. Fungi: Candida, Aspergillus

4. Protozoa: Pneumocystis jiroveci, Toxoplasma Gondi, Cryptosporidium paroum

- B cell immunodeficiency (Presents when weaning is started and breastfeeding stops)

1. Bacteria: S. pneumonia, H. influenza, M. catarrhalis, $P$. aeruginosa, S. aureus, N. meningitidis, M. pneumonia

2. Viruses: Enteroviruses

3. Protozoa: Giardia lamblia

- Congenital defects of phagocyte number and function (Can present at any age based on the severity of the defect)

1. Bacteria: S.aureus, P. aeruginosa, Nocardia, S. Typhi

2. Fungi: Candida, Aspergillus

3. Mycobacteria: Nontuberculous including BCG
- Complement deficiencies ( Can present as early as within 6 months of life)

1. Bacteria: Streptococci, H. influenza, Neisseria,

2. Viruses: CMV, HSV

The European Society for Immunodeficiency (ESID) clinical guidelines proposed the grouping of immunodeficiency, syndromes and likely infections as follows (Table 2).

Table 2: The types of clinical patterns of presentation and infections in PIDs

\begin{tabular}{|c|c|c|}
\hline Immunodeficiency & Infections & Example \\
\hline $\begin{array}{l}\text { Antibody } \\
\text { deficiency } \\
\text { Phagocyte } \\
\text { deficiency } \\
\text { Complement } \\
\text { deficiency }\end{array}$ & $\begin{array}{l}\text { Bronchiectasis, } \\
\text { rhinosinusitis }\end{array}$ & $\begin{array}{l}\text { HIV, Wiskott-Aldrich } \\
\text { Syndrome }\end{array}$ \\
\hline $\begin{array}{l}\text { T-lymphocyte } \\
\text { deficiency }\end{array}$ & $\begin{array}{l}\text { Chronic diarrhea, } \\
\text { Candida/ PCP, } \\
\text { Mycobacteria }\end{array}$ & SCID /HIV \\
\hline Neutrophil defects & $\begin{array}{l}\text { Recurrent pyogenic } \\
\text { infections, } \\
\text { Invasive Aspergillus, } \\
\text { Burkholderia }\end{array}$ & $\begin{array}{l}\text { Chronic } \\
\text { granulomatous } \\
\text { disease } \\
\text { (CGD) }\end{array}$ \\
\hline $\begin{array}{l}\text { Defects of innate } \\
\text { immunity(TLR3) } \\
\text { T-lymphocyte } \\
\text { deficiency }\end{array}$ & $\begin{array}{l}\text { Invasive } \\
\text { pneumococcal } \\
\text { disease } \\
\text { Herpes Simplex } \\
\text { Encephalitis }\end{array}$ & $\begin{array}{l}\text { SCID/ HIV } \\
\text { Wiskott-Aldrich } \\
\text { Syndrome }\end{array}$ \\
\hline $\begin{array}{l}\text { T lymphocyte/ } \\
\text { macrophage } \\
\text { deficiency }\end{array}$ & $\begin{array}{l}\text { Meningococci, } \\
\text { encapsulated } \\
\text { bacteria or Candidal } \\
\text { Mycobacteria }\end{array}$ & \\
\hline $\begin{array}{l}\text { Common variable } \\
\text { immunodeficiency } \\
\text { (CVID) }\end{array}$ & $\begin{array}{l}\text { Autoimmune or } \\
\text { chronic } \\
\text { inflammatory disease }\end{array}$ & $\begin{array}{l}\text { Haemophagocytic } \\
\text { lymphohistiocytosis } \\
(\mathrm{HLH})\end{array}$ \\
\hline
\end{tabular}

In ICU setting in patients with PID; following organisms are likely to cause infections.

- B cell deficiency

1. Pneumococcus

2. H. influenza

3. Staph Aureus

4. Giardia Lamblia

5. Viruses Enterovirus/echovirus

- T cell deficiency

1. Mycobacteria

2. Viruses: $\mathrm{CMV} / \mathrm{EBV} / \mathrm{HSV} / \mathrm{RSV} / \mathrm{VZ} /$ Parainfluenza

3. Fungi: P.carini, Histoplasma, cryptosporidium, Toxoplasma

- Phagocytic disorder

1. Gram Negative: E.coli/ Klebsiella/ B.cepacia/ Pseudomonas/Serratia

2. Gram positive: Staph / Nocardia/Listeria/

3. Fungus: Aspergillus and candida

- Defects in the complement system: Streptococcus pneumonia and Neisseria 
- Mendelian susceptibility to Mycobacterium (MSMD): Mycobacteria, salmonella typhi, and nontyphii, listeria, viral and other intracellular pathogens (e.g., Histoplasma, leishmania). ${ }^{6-11}$

- We recommend intravenous immunoglobulin for treatment of all antibody deficiency diseases (UPP, A). The recommended dose is $400 \mathrm{mg} / \mathrm{kg} /$ doses every 4 weekly. We recommend $2 \mathrm{gm} / \mathrm{kg}$ single dose (severe infections) or $1 \mathrm{gm} / \mathrm{kg}$ weekly till infection subsides (UPP, A).

- We recommend to maintain serum IgG trough levels above $500 \mathrm{mg} / \mathrm{dL}$ and above $700 \mathrm{mg} / \mathrm{dL}$ in bronchiectasis (Level III, A).

- We recommend thoracic computed axial tomography, lung function tests with spirometry and DLCO every 6 months after discharge (UPP, A).

- We recommend hematopoietic stem cell transplantation in cellular and macrophage immunodeficiency (UPP, A).

- We recommend monoclonal antibodies such as rituximab only in autoimmune complications related to CVID (UPP, A).

- We recommend Rituximab be given in PID complicated with EBV viremia (UPP, A).

- We recommend for all critically Ill patients with suspicion of PID the empirical antimicrobial treatment with IV Carbapenems with IV Vancomycin/Teicoplanin for broad-spectrum coverage (UPP, A). Voriconazole is the preferred antifungal in case of proven, possible or probable invasive fungal infection with Aspergillus (I, A).

- In critically ill patients diagnosed with Combined B and $\mathrm{T}$ cell deficiency, the antimicrobial drug of choice is IV Carbapenems with Vancomycin/Teicoplanin and Trimethoprim-Sulfamethoxazole (UPP, A).

- In critically ill patients diagnosed with Combined B and $\mathrm{T}$ cell deficiency with suspicion of viral infections, we recommend: (UPP, A).

1. IV Acyclovir if herpes group of infection is suspected

2. Oral Oseltamivir if Influenza virus is suspected

3. IV Ganciclovir if CMV is suspected radiologically or by laboratory tests

- In critically ill patients diagnosed with B cell deficiency, based on the organisms expected (Capsulated), we recommend IV ceftriaxone with IV Vancomycin/ Teicoplanin (UPP, A).

- We recommend IV immunoglobulin (IVIG) at a dose of $1 \mathrm{gm} / \mathrm{kg}$ weekly in cases of severe infections especially $\mathrm{ECHO} /$ Enterovirus/Polio virus-induced encephalitis (UPP, A).

- In critically ill patients diagnosed with Phagocyte disorder, we recommend antimicrobial drug of choice to be IV Carbapenems with IV Vancomycin/Teicoplanin and Voriconazole (UPP, A)

- We Recommend the use of Granulocyte-colony stimulating factor (GCSF) in patients of congenital Neutropenia. (UPP, A)

- In critically ill patients diagnosed with complement deficiency, the antimicrobial drug of choice is IV Cephalosporin (UPP, A).

\section{Evidence Summary}

The data regarding the use of Antibiotics in Immunodeficiency states are scarce. The experts recommend using antibiotic as per organism isolated or expected. Generally, the management depends upon the type of PID.

\section{Therapy includes}

- IV Immunoglobulin (IVIG) infusion mainly for B cell deficiency. ${ }^{12-14}$

- Antibiotics as per suspected source of infection and suspected organism

- Rituximab in PID with Epstein Barr virus reactivation Stem cell transplant is the most curative option for the majority of the PID. Paradoxically Rituximab treatment has known to aggravate primary immunodeficiency or hypogammaglobulinemia in a certain group of patients, and appropriate care has to be taken in these patients. In PID such as X-linked Lymphoproliferative disorder, Rituximab can be given once in 4 weeks to decrease the EBV Viral load. ${ }^{1,3,4}$

\section{Vaccinations and Antimicrobial Prophylaxis at Discharge}

\section{Evidence Statements}

- We wish to emphasize that all forms of live vaccines, viral and bacterial, are contraindicated in patients with SCID (UPP, A).

- We recommend vaccination for diagnosed patients with complement deficiency at the time of discharge (UPP, A). We recommend to avoid BCG vaccination in chronic granulomatous disease/MSMD patient (UPP, A).

- We recommend antifungal, and anti PCP prophylaxis for all patients diagnosed with PID shifted from ICU. (UPP A). PID patients with the chronic granulomatous disease the drug of choice is Itraconazole (I, A) and Trimethoprim-Sulfamethoxazole (II, A).

PCP prophylaxis should be given to all patients with Combined $\mathrm{B}$ and $\mathrm{T}$ or $\mathrm{T}$ cell deficiency with the drug of choice being Trimethoprim-Sulfamethoxazole (I, A). We recommend antifungal prophylaxis in all patients with T cell defects (III, A) 


\section{Evidence Summary}

Vaccine recommendations should be earmarked only for patients with certain PID.

Live vaccines are avoided in patients with severe Band T-cell dysfunction due to the risk of dissemination and the futility of immune response. All vaccines are safe and effective in the patients with complement deficiency (susceptibility to encapsulated organisms). ${ }^{15-17}$

\section{REFERENCES}

1. Gupta S, Madkaikar M, Singh S, Sehgal S. Primary immunodeficiencies in India: a perspective. Ann N Y Acad Sci. 2012;1250:73-9.

2. Jindal AK, Pilania RK, Rawat A, Singh S. Primary Immunodeficiency Disorders in India-A Situational Review. Front Immunol. 2017;8:714.

3. Madkaikar M, Mishra A, Desai M, Gupta M, Mhatre S, Ghosh K. Comprehensive Report of Primary Immunodeficiency; Disorders from a Tertiary Care Center in India. J Clinical Immunology. 2013; 33:507-512.

4. Madkaikar M, Mishra A, Ghosh K. Diagnostic Approach to Primary Immunodeficiency Disorders; Indian Pediatrics; 2013; 50: 579-86.

5. Halliday E, Winkelstein J, Webster AD. Enteroviral Infections in Primary Immunodeficiency (PID): A Survey of Morbidity and Mortality; J Infect. 2003;46:1-8.

6. Antachopoulos C, Walsh TJ, Roilides E. Fungal infections in primary immunodeficiencies; Eur J Pediatr. 2007; 66:1099-117.

7. Ram S, Lewis LA, Rice PA. Infections of people with complement deficiencies and patients who have undergone splenectomy. Clin Microbiol Rev. 2010;23:740-80
8. Odek C, Kendirli T, Do u F, Yaman A, Vatansever G, Cipe F, Haskolo lu S, et al. Patients with primary immunodeficiencies in pediatric intensive care unit: outcomes and mortalityrelated risk factors. J Clin Immunol. 2014;34:309-15

9. El Habbal MH, Strobel S. Leukocyte adhesion deficiency. Arch Dis Child 1993;69:463-6.

10. Bousfiha A, Jeddane L, Picard C, Ailal F, Bobby Gaspar H, Al-Herz W, Chatila T, et al. The 2017 IUIS Phenotypic Classification for Primary Immunodeficiencies. J Clin Immunol. 2018;38:129-143.

11. Abolhassani H, Sagvand BT, Shokuhfar T, Mirminachi $\mathrm{B}$, Rezaei N, Aghamohammadi A. A review on guidelines for management and treatment of common variable immunodeficiency; Expert Rev Clin Immunol. 2013;9:561-575.

12. Boyle ML, Scalchunes C. Impact of intervenous immunoglobulin (IVIG) treatment among patients with Primary Immunodeficiency diseases. Pharmaceuticals Policy and Law 2008;10:133-146.

13. Shabani M, Nichols KE, Rezaei N.Primary immunodeficiencies associated with EBV-Induced lymphoproliferative disorders. Critical Reviews in Oncology /Hematology 2016; 108: 109-127.

14. Bonagura VR. Using intravenous immunoglobulin (IVIG) to treat patients with primary immune deficiency disease. J Clin Immunol. 2013;33 Suppl 2:S90-4.

15. Freeman AF, Holland SM. Antimicrobial prophylaxis for primary immunodeficiencies. Curr Opin Allergy Clin Immunol. 2009;9:525-30.

16. Rubin LG, Levin MJ, Ljungman P, Davies EG, Avery R, Tomblyn M, Bousvaros A, et al. 2013 IDSA clinical practice guideline for vaccination of the immunocompromised host. Clin Infect Dis 2014; 58:e44-100

17. Brady MT, Bernstein HH, Byington CL, Edwards KM, Fisher MC, Glode MP, Jackson MA et al for Committee on Infectious Diseases.Meningococcal conjugate vaccines policy update: booster dose recommendations. Pediatrics 2011;128:1213-8. 
${ }_{1}^{1}$ Professor and Head, Division of Critical Care Medicine, Department of Anaesthesiology, Critical Care and Pain, Tata Memorial Hospital, Homi Bhabha National Institute, Dr Ernest Borges Road, Parel, Mumbai, Maharashtra, India

${ }^{2}$ Professor, Department of Medical Oncology, Tata Memorial Centre, Homi Bhabha National Institute, Dr Ernest Borges Road, Parel, Mumbai, Maharashtra, India

${ }^{3}$ Professor, Department of Paediatric Oncology, Tata Memorial Centre, Homi Bhabha National Institute, Dr Ernest Borges Road, Parel, Mumbai, Maharashtra, India

${ }^{4}$ Consultant in Medicine and Critical Care, PD Hinduja National Hospital, Mahim, Mumbai, Maharashtra, India

${ }^{5}$ Consultant Microbiologist and Chair Infection Control, Hinduja Hospital, Mahim, Mumbai, Maharashtra, India

${ }^{6}$ Consultant ID Physician, Jupiter Hospital, Pune, DeenanathMangeshkar Hospital, Pune, BharatiVidyapeeth, Deemed University Hospital, Pune, Courtsey Visiting Consultant,Hinduja Hospital Mumbai, Maharashtra, India

${ }^{7}$ Professor and Head, Department of Pulmonary Medicine and Sleep Disorders, All India Institute of Medical Sciences, New Delhi, India ${ }^{8}$ Sr Consultant, Pulmomary and Critical Care Medicine, Apollo Gleneagles Hospital, 58, Canal Circular Road, Kolkata, West Bengal, India ${ }^{9} \mathrm{Head}$ Department of Immunology, Prof of Pediatric Hematology and Oncology, Bai Jerbaiwadia Hospital for Children, Consultant, Hematologist, Nanavati Superspeciality Hospital, Director of Pediatric Hematology, Surya Hospitals, Mumbai, Maharashtra, India

${ }^{10}$ Director, Intensive Care Unit,Fortis Hospital, Mulund Goregaon Link Road, Mulund (W), Mumbai, Maharashtra, India

${ }^{11}$ Consultant and Head of Department, Critical Care Medicine, Ashoka - Medicover Hospital, Indira Nagar, Wadala Nashik, Maharashtra, India

${ }^{12}$ Consultant Microbiologist, Microbiology Section, 5th Floor, S1 Building, PD Hinduja Hospital, Veer Savarkar Marg, Mahim, Mumbai, Maharashtra, India

${ }^{13}$ Consultant Physician in Infectious Disease, Unison Medicare and Research Centre and Prince Aly Khan Hospital, Maharukh Mansion, Alibhai Premji Marg, Grant Road, Mumbai, Maharashtra, India

${ }^{14}$ Associate Professor Intensive Care Medicine, Department of Anaesthesia, Critical Care and Pain, Tata Memorial Center, Homi Bhabha National Institute, Dr. E. Borges Road, Parel, Mumbai, Maharashtra, India

${ }^{15}$ Associate Professor, Division of Critical Care Medicine, Departemnt of Anaesthesia, Critical Care and Pain, Tata Memorial Center, Homi Bhabha National Institute, Dr. E. Borges Road, Parel, Mumbai, Maharashtra, India

${ }^{16}$ Consultant in Critical Care, Director, ICU Sanjeevan and MJM Hospital, Pune, Maharashtra, India

${ }^{17}$ Director and HOD, Neuro-Trauma Unit, Grant Medical Foundation, Ruby Hall Clinic, Pune, Maharashtra, India

${ }^{18}$ Adjunct Professor - NBE, Chairman - Medanta Institute of Critical Care and Anesthesiology, Medanta The Medicity, Gurgaon, Haryana, India

${ }^{19}$ Senior Resident, Division of Critical Care Medicine, Department of Anesthesia, Critical Care and Pain, Tata Memorial Hospital, Homi Bhabha National Institute, Dr E Borges Road, Mumbai, Maharashtra, India

${ }^{20}$ Specialist Senior Registrar, Department of Anaesthesia, Critical Care and Pain, Tata Memorial Center, HomiBhabha National Institute, Dr. E. Borges Road, Parel, Mumbai, Maharashtra, India

${ }^{21}$ Specialist Senior Registrar, Department of Anaesthesia, Critical Care and Pain, Tata Memorial Center, Homi Bhabha National Institute, Dr. E. Borges Road, Parel, Mumbai, Maharashtra, India

${ }^{22}$ Specialist Senior Registrar, Division of Critical Care Medicine, Department of Anaesthesia, Critical Care and Pain, Tata Memorial Center, Homi Bhabha National Institute, Dr. E. Borges Road, Parel, Mumbai, Maharashtra, India

${ }^{23}$ Senior Registrar (Senior Resident), Division of Critical Care Medicine, Department of Anaesthesia, Critical Care and Pain, Tata Memorial Center, Homi Bhabha National Institute, Dr. E. Borges Road, Parel, Mumbai, Maharashtra, India

${ }^{24}$ Senior Registrar, Division of Critical Care Medicine, Department of Anaesthesia, Critical Care and Pain, Tata Memorial Center, Homi Bhabha National Institute, Dr. E. Borges Road, Parel, Mumbai, Maharashtra, India

${ }^{25}$ Senior Registrar, Division of Critical Care Medicine, Department of Anaesthesia, Critical Care and Pain, Tata Memorial Center, Homi Bhabha National Institute, Dr. E. Borges Road, Parel, Mumbai, Maharashtra, India

${ }^{26}$ Assistant Professor, Department of Medical Oncology, Tata Memorial Hospital, HomiBhabha National Institute, Mumbai, Maharashtra, India

${ }^{27}$ Assistant Professor, Department of Pediatric Oncology, Tata Memorial Hospital, HomiBhabha National Institute, Dr E. Borges Marg, Parel, Mumbai, Maharashtra, India

${ }^{28}$ Consultant, Critical Care, Fortis Hospital, 102, Nav Sai Shakti CHS, Near Bhoir Gymkhana, M Phule Road, Dombivali West Mumbai, Maharashtra, India

${ }^{29}$ Junior Consultant, Critical Care Medicine, PD Hinduja National Hospital and MRC, Mumbai, Maharashtra, India

${ }^{30}$ Professor and Head, Department of Anaesthesia, Critical Care and Pain, Tata Memorial Hospital, Homi Bhabha National Institute, Dr. E. Borges Road, Parel, Mumbai, Maharashtra, India 